\title{
Endothelial Dysfunction and Therapeutic Intervention in Type 2 Diabetes
}

\author{
Fernando Grover Páez \\ Centro Universitario de Ciencias de la Salud, Universidad de Guadalajara \\ México
}

\section{Introduction}

Diabetes mellitus (DM) is a major risk factor for micro and macrovascular complications (Kannel \& McGee, 1979; King \& Sheetz, 2002), and is associated with endothelial dysfunction, premature atherosclerosis (Johnstone et al., 1993; Nathan et al., 2003; Williams et al., 2005), and a reduced capability of neovascularization in ischemic conditions (Abaci et al., 1999). Hyperglycemia increases the production of superoxide (O2-) and reduces the bioavailability of nitric oxide (NO) resulting in the development of endothelial dysfunction in diabetic patients (Creager et al., 2003; Loomans et al., 2005). Exposure to oxidative stress induces a pro-inflammatory response and increases endothelial cell apoptosis, which leads to a disturbance in the endothelial monolayer. The denuded vessel wall is highly proatherogenic, so fast regeneration of the endothelium is essential to prevent formation of atherosclerotic plaques (Dimmeler et al., 2002; Dimmeler \& Zeiher, 2004).

Patients with type 2 diabetes suffer disturbances in the intermediate metabolism of carbohydrates, proteins and lipids, caused by poor insulin secretion what leads to chronically sustained hyperglycemia. As a result, insulin-resistance develops in target organs and at peripheral sites, the main cause of the pathogenesis related to type 2 diabetes (Cerrato, 2004). Hyperinsulinemia promotes atherogenesis through cell proliferation at the vascular wall which produces endothelial damage (Mátthael \& Stumvall, 2001). These endothelial alterations induce the early appearance of atherosclerosis, altering vascular homeostasis mainly due to the interaction of nitric oxide (NO) and free oxygen radicals. As a consequence of this interaction the endothelial anti-inflammatory and vasodilator properties are perturbed which leads to endothelial cell death, proliferation and inadequate restructuring of the vascular walls (Galle et al., 2003). While endothelial damage and the underlying inflammatory processes are often detected later, endothelial damage occurs before the atherosclerotic plate can be identified (Bots et al., 1997). There are many biomarkers for inflammation and early endothelial dysfunction that can be used to identify endothelial damage in order to prevent cardiovascular disease (CD), including: high sensitivity $\mathrm{C}$ reactive protein (hs-CRP), homocysteine, microalbuminuria, glycosylated hemoglobin (A1c), Von Willebrand factor and plasminogen-activator inhibitor type 1 (Reinhart et al., 2002). Elevated hs-CRP appears to be a strong predictor for future cardiovascular events (Tornel et al., 2003). On the other hand, much interest has been generated in determining serum homocysteine levels due to the relationship with CD (de Luis et al., 2004). Indeed, elevated serum homocysteine levels have been associated with a 
greater risk of developing thrombosis, as well as an increase in the production of hydrogen peroxide and in the oxidation of low-density lipoprotein cholesterol (LDL-C), leading to endothelial damage (Retterstol et al., 2003). At the same time, while microalbuminuria is an important risk factor for nephropathy in type 1 diabetes patients, in type 2 diabetes patients it serves as a predictor of CD (Festa et al., 2000).

Over the last two decades it has become evident that the endothelium is not an inert, singlecell lining covering the internal surface of blood vessels, but in fact plays a crucial role in regulating vascular tone and structure. Importantly, a healthy endothelium inhibits platelet and leukocyte adhesion to the vascular surface and maintains a balance of profibrinolytic and prothrombotic activity (Libby, 2002). Endothelial dysfunction has received increasing attention as a potential contributor to the pathogenesis of vascular disease in diabetes mellitus. Under physiological conditions, there is a balanced release of endothelial-derived relaxing and contracting factors, but this delicate balance is altered in diabetes and atherosclerosis, thereby contributing to further progression of vascular and end-organ damage (Tan et al., 2002).

Hyperglycemia is the major causal factor in the development of endothelial dysfunction in diabetes mellitus. Although the mechanisms underlying this phenomenon are likely to be multifactorial. Insulin resistance has been described in several diseases that increase cardiovascular risk and mortality, such as diabetes, obesity, hypertension, metabolic syndrome, and heart failure. Increasing evidence suggests that the progression of insulin resistance to type 2 diabetes parallels the progression of endothelial dysfunction to atherosclerosis. Insulin resistance is closely linked with visceral adiposity, and early data suggested that free fatty acids were responsible for this association (Boden \& Shulman, 2002). More recently, other plasma biomarkers produced by adipose tissue, including TNF and resistin, have been shown to have elevated levels during obesity and to mediate insulin resistance. Conversely, the expression and secretion of adiponectin, an adipocyte-specific protein that enhances insulin-mediated glucose uptake, is inversely correlated with fat mass (Lyon et al., 2003). Several studies have demonstrated that nitric oxide (NO)-mediated vasodilation is abnormal in patients with type 2 diabetes (Williams et al., 1996). Brachial artery responses were found to be abnormal to both endogenous and exogenous $\mathrm{NO}$ donors, suggesting that there was increased inactivation of NO, possibly caused by enhanced metabolism of NO or abnormal vascular smooth muscle cell (VSMC) responses to $\mathrm{NO}$ because of alterations in signal transduction in the guanylate cyclase pathway. Obese patients without frank type 2 diabetes have been shown also to have abnormal endothelial function (Perticone et al., 2001; Steinberg et al., 1996).

Diminished capacity of NOS to generate NO has been demonstrated experimentally when ECs are exposed either in vitro or in vivo to a diabetic environment (Cosentino \& Luscher, 1998; Huszka et al., 1997; Huvers et al., 1999; Lambert et al., 1996). The EC is then a target of the diabetic milieu and endothelial dysfunction is thought to play an important role in the vasculopathy of this disease state. A large body of evidence in humans indicates that endothelial dysfunction is closely associated to microangiopathy and atherosclerosis in both types 1 and 2 diabetes mellitus (Cosentino \& Luscher, 1998). This association is particularly true in those patients with type 1 diabetes who have either early (microalbuminuria) or late (macroalbuminuria) nephropathy. In these patients, a great variety of markers indicate endothelial dysfunction: poor EC-dependent vasodilation, increased blood levels of von Willebrand factor (vWF), thrombomodulin, selectin, PAI-1, type IV collagen, and t-PA (Cosentino \& Luscher, 1998; Furchgott \& Zawadzki, 1980; Schneider et al., 2002). Once 
established, EC dysfunction can, in turn, induce alterations in vessels that worsen vasculopathy and progress disease. Hyperglycemia may lead to intracellular changes in the redox state resulting in depletion of the cellular NADPH pool. Overexpression of growth factors has also been implicated in diabetes with proliferation of both endothelial cells and vascular smooth muscle, possibly promoting neovascularization. The diabetic state is typified by an increased tendency for oxidative stress and high levels of oxidized lipoproteins, especially the so-called small, dense low-density lipoprotein. The high levels of fatty acids and hyperglycemia have also both been shown to induce an increased level of oxidation of phospholipids as well as proteins. In humans it is associated with a prothrombotic tendency as well as increased platelet aggregation, with tumor necrosis factor implicated as a link between insulin resistance, diabetes, and endothelial dysfunction; a hypothesis has been advanced that insulin and/or insulin precursors may be atherogenic. The general consensus is that the occurrence of endothelial cell dysfunction in type 1 diabetes signifies a very high risk of micro- and macroangiopathy, and although the diabetic state predisposes to endothelial cell dysfunction in this disease, it is not sufficient to cause it. It is more likely that other agents (genes, environment) have a role in determining which patients will develop aggressive angiopathy and hence endothelial cell dysfunction. Irrespective of whether endothelial cell dysfunction is a cause or a consequence of vascular injury in type 1 diabetes, it is hoped that therapeutic efforts aimed at restoring endothelial cell function to normal will affect the natural history of vasculopathy in type 1 diabetes (Cosentino \& Luscher, 1998). Impaired endothelium-dependent vasodilatation has been demonstrated in various vascular beds of different animal models of diabetes and in humans with type 1 and 2 diabetes. Several mechanisms of endothelial dysfunction have been reported, including impaired signal transduction or substrate availibility, impaired release of endothelium-derived relaxing factors (EDRF), increased destruction of EDRF, enhanced release of endothelium-derived constricting factors and decreased sensitivity of the vascular smooth muscle to EDRF. The principal mediators of hyperglycemia-induced endothelial dysfunction may be activation of protein kinase $C$, increased activity of the polyol pathway, nonenzymatic glycation and oxidative stress. Both insulin and glucose play a role in ET-1 release. Insulin activates ET-1 production by endothelial cells, and hyperglycemia leads to the formation of advanced glycation end products (AGEs) that promote ET-1 production by endothelial cells through the activation of transcription factor NF-kB. Diabetic patients, both those with type I diabetes and those with insulin resistance, present increased ET-1 plasma concentrations. AGEs are known to trigger vascular inflammation and endothelial dysfunction. The hyperglycemia associated with diabetes can lead to modification of macromolecules, for example, by forming AGEs. By binding surface receptors such as RAGE (receptor for AGE), these AGE-modified proteins can augment the production of proinflammatory cytokines and other inflammatory pathways in vascular endothelial cells. Beyond the hyperglycemia, the diabetic state promotes oxidative stress mediated by reactive oxygen species and carbonyl groups (Cosentino \& Luscher, 1998; Huszka et al., 1997; Huvers et al., 1999; Lambert et al., 1996 Furchgott \& Zawadzki, 1980; Schneider et al., 2002; Quehenberger et al., 2000; O'Brien et al., 1997).

In patients with a high risk of developing $C D$, such as diabetic patients, it is important to improve endothelial function since vascular damage may continue even when good glycemic control has been achieved (Volpe et al., 2007). Accordingly, some therapeutic strategies have been directed towards the stimulation of distinct processes that may reestablish the function of the endothelium, including the use of 3-hydroxy-3-methylglutaryl 
coenzyme A reductase inhibitors (Endemann \& Schiffrin, 2004), the angiotensin converting enzyme (ACE) inhibitors (Schachinger et al., 2000), selective blockade of the AT1 receptor of angiotensin-II (ARBs) (Behrendt \& Ganz, 2002) and folic acid supplementation (Libby et al., 2002), antioxidants (Beckman et al., 2003), antidiabetics (Lund et al., 2008), insulin (Vehkavaara et al., 2000) and others (Grover-Páez et al., 2007). All these strategies are aimed at decreasing the progress of atherosclerotic disease

Herein, we review the literature about endothelial dysfunction in diabetes mellitus with regards to its pathogenesis at molecular and clinical level, and possible available mode of therapy.

\section{Normal endothelial cell (EC) function}

The EC is no longer considered a simple barrier. In fact it is a complex organ, with paracrin and autocrin function, which provides a "first line" physiological defense against atherosclerosis. The EC lines the internal lumen of all the vasculature and serves as an interface between circulating blood and vascular smooth muscle cells (VSMC). In addition to serving as a physical barrier between the blood and tissues, the EC facilitates a complex array of functions in intimate interaction with the VSMC, as well as cells within the blood compartment (De Meyer \& Herman, 1997).

The last two decades of research have established unambiguously that the EC has a critical role in overall homeostasis whose functions are integrated by a complicated system of chemical mediators. This system exerts effects on both the surrounding VSMC and the cells in the blood that lead to one or more of the following alterations: (1) vasodilatation or vasoconstriction to regulate organ blood, (2) maintenance of fluidity of blood and avoidance of bleeding, (3) proinflammatory or anti-inflammatory changes, and (4) growth and/or changes in the phenotypic characteristics of VSMC (Wautier et al., 1996). During the last decade, a multitude of experimental arguments have led to the concept that NO is not only involved in the control of vasomotor tone but also in vascular homeostasis and neuronal and immunological functions. Endogenous NO is produced through the conversion of the amino acid, l-arginine to l-citrulline by the enzyme, NO-synthase (NOS) from which several isoforms have recently been isolated, purified, and cloned. NOS-type I (isolated from brain) and type III (isolated from ECs) are termed "constitutive-NOS" and produce picomolar levels of NO from which only a small fraction elicits physiological responses. NO produced by NOS type III in the endothelium diffuses to the vascular smooth muscle (VSM) where it activates the enzyme guanylate cyclase. The concomitant increase in cyclic GMP then induces relaxation of the VSM. The EC produces mediators that induce vasoconstriction, including endothelin (Haefliger, 1992) [46], prostaglandins (Viberti, 1989) and angiotensin II (ANG-II) (Studdy, 1983) and regulates vascular tone by maintaining a balance between vasodilation (NO production) and vasoconstriction (eg, A-II generation). ANG-II is produced in local tissues by the EC (Mombouli, 1997) [49] and exerts regulatory effects upon several VSMC functional activities including contraction (ie, vasoconstriction), growth, proliferation, and differentiation. NOS also are regulated by local concentrations of bradykinin (Busse et al.,1993). This peptide acts with b2 receptors on the EC cell surface membrane, increasing the generation of NO via NOS activation. Interestingly, the local concentrations of bradykinin are regulated by the activity of angiotensin converting enzyme (ACE). ACE breaks down bradykinin into inactive peptides (Luscher et al., 1993). Furthermore the EC has a prominent role in maintaining blood fluidity and restoration of 
vessel wall integrity to avoid bleeding and plays a key role in the balance between the coagulation and fibrinolytic systems. In addition to its key role in growth and differentiation of the VSMC through the release of either promoters of growth and/or inhibitors of growth and differentiation and, as such, has an impact on vascular remodeling (Cowan \& Langille, 1996). However, strong evidence suggests that promotion of VSM growth is mediated by local production of platelet growth factor (PGF) and ANG-II (Williams, 1998). The EC is also involved in the production of specific molecules that have a regulatory role in inflammation such as leukocyte adhesion molecule (LAM), intracellular adhesion molecule (ICAM) and vascular cell adhesion molecule (VCAM). These molecules are denominated "adhesion molecules" and function to attract and "anchor" those cells involved in the inflammatory reaction. Very recently it has been demonstrated that the atherosclerotic process is associated with an increased blood level of inflammation (acute phase proteins) markers (Biegelsen \& Loscalzo, 1999).

\subsection{Endothelial dysfunction}

Since the actions of the EC are multiple and involve several systems, alterations in EC function may affect one or more of these systems, either simultaneously or at distinct time periods. Thus, no single definition of EC dysfunction covers the whole array of possible disruption in normal function. In consequence, endothelial dysfunction has been defined pragmatically. It basically involves either an increase (or a decrease) in any of the EC-related chemical messenger and/or by alteration in any of the functional changes. Some examples of EC dysfunction include an increased permeation of macromolecules (Aird, 2005; Forstermann \& Munzel, 2006; Ross, 1993; Vita \& Keaney, 2002), increased or decreased production of vasoactive factors producing abnormal vasoconstriction/vasodilation, and increased prothrombotic and/or procoagulant activity. However, the most commonly accepted EC dysfunction alteration pertains to abnormalities in the regulation of the lumen of vessels. In this context, EC dysfunction has been defined by blunting of the vasodilatory response to acetylcholine or hyperemia, both of which are known to produce NO-dependent vasodilation. In some specific circumstances, endothelial dysfunction has been defined by a paradoxical vasoconstrictive response to acetylcholine or similar pharmacological agents (i.e., metacholine). At the heart of the definition of EC dysfunction is the measurement of EC function.

Endothelial dysfunction is defined by an impaired vascular reactivity, but it also refers to a proinflammatory and prothrombotic state. A critical balance between endothelium-derived relaxing and contracting factors maintains vascular homeostasis. When this balance is disrupted, it predisposes the vasculature to vasoconstriction, leukocyte adherence, platelet activation, mitogenesis, pro-oxidation, thrombosis, impaired coagulation, vascular inflammation, and atherosclerosis. Endothelial dysfunction has been described in many cardiovascular and metabolic disorders such as hypertension, coronary heart disease, dyslipidemia, and type I and II diabetes. Endothelial dysfunction appears to precede the clinical manifestations of many of these cardiovascular disorders, hypertension for example, and also atherosclerosis, where abnormal vasoconstriction can be observed at the future site of plaque development (Aird, 2005; Endemann \& Schiffrin, 2004; Forstermann \& Munzel, 2006; Schachinger et al., 2000; Volpe et al., 2007). Thus, endothelial dysfunction is one of the earliest hallmarks of vascular abnormality.

Endothelial dysfunction is thought to precede the development of atherosclerosis. Indeed, in the presence of cardiovascular risk factors endothelial dysfunction can be detected before 
there is any angiographic evidence of disease or increased intima-media ratio on ultrasound examination. Many of the cardiovascular risk factors, including hyperlipidemia, hypertension, diabetes and smoking, are associated with overproduction of reactive oxygen species or increased oxidative stress, both of which reduce vascular nitric oxide bioavailability and promote cellular damage (Volpe et al., 2007). Hence, increased oxidative stress is considered to be a major mechanism involved in the pathogenesis of endothelial cell dysfunction and may serve as a common pathogenic mechanism of the effect of risk factors on the endothelium (Aird, 2005; Schachinger et al., 2000).

\subsection{Endothelial dysfunction and atherosclerosis}

Atherosclerosis is regarded as a dynamic and progressive disease arising from the combination of endothelial dysfunction and inflammation. Physiological laminar shear stress is of particular importance in protecting EC against abnormal activation. Endothelial activation can be observed under specific hemodynamic conditions such as prolonged low or oscillatory shear stress. These conditions are responsible for plaque formation and plaque vulnerability in mouse carotid artery. Both low and oscillatory shear stress increase ET-1 expression while decreasing endothelial NO synthase (eNOS) expression. The increase in ET-1 expression may lead to vascular inflammation, which is central to all stages of atherosclerosis. ET-1 induces expression of adhesion molecules on isolated endothelial cells, promotes vascular inflammation and excessive oxidative stress, and mediated nuclear factor-kB (NFkB) activation in monocytes. In a variety of animal models of atherosclerosis, signs of inflammation occur hand-in-hand with incipient lipid accumulation in the artery wall. For example, blood leukocytes, mediators of host defenses and inflammation, localize in the earliest lesions of atherosclerosis, not only in experimental animals but in humans as well. The basic science of inflammation biology applied to atherosclerosis has afforded considerable new insight into the mechanisms underlying this recruitment of leukocytes. The normal endothelium does not in general support binding of white blood cells. However, early after initiation of an atherogenic diet, patches of arterial endothelial cells begin to express on their surface selective adhesion molecules that bind to various classes of leukocytes. In particular, vascular cell adhesion molecule-1 (VCAM-1) binds precisely the types of leukocytes found in early human and experimental atheroma, the monocyte and $\mathrm{T}$ lymphocyte. Not only does VCAM-1 expression increase on endothelial cells overlying nascent atheroma, but mice genetically engineered to express defective VCAM-1 show interrupted lesion development (Aird, 2005; Behrendt \& Ganz, 2002; Forstermann \& Munzel, 2006; Ishizuka et al., 1999; Li et al., 1993). Interestingly, the foci of increased adhesion molecule expression overlap with sites in the arterial tree particularly prone to develop atheroma. Considerable evidence suggests that impaired endogenous atheroprotective mechanisms occur at branch points in arteries, where the endothelial cells experience disturbed flow. For example, absence of normal laminar shear stress may reduce local production of endothelium-derived NO. This endogenous vasodilator molecule also has anti-inflammatory properties and can limit expression of VCAM-1. In addition to inhibiting natural protective mechanisms, disturbed flow can augment the production of certain leukocyte adhesion molecules (eg, intercellular adhesion molecule-1 [ICAM-1]). Augmented wall stresses may also promote the production by arterial smooth muscle cells (SMCs) of proteoglycans that can bind and retain lipoprotein particles, facilitating their oxidative modification and thus promoting an inflammatory response at sites of lesion formation. Once adherent to the endothelium, the leukocytes penetrate into the intima. 
Recent research has identified candidate chemoattractant molecules responsible for this transmigration. For example, monocyte chemoattractant protein-1 (MCP-1) appears responsible for the direct migration of monocytes into the intima at sites of lesion formation. A family of T-cell chemoattractants may likewise call lymphocytes into the intima. Once resident in the arterial wall, the blood-derived inflammatory cells participate in and perpetuate a local inflammatory response. The macrophages express scavenger receptors for modified lipoproteins, permitting them to ingest lipid and become foam cells. In addition to MCP-1, macrophage colony-stimulating factor (M-CSF) contributes to the differentiation of the blood monocyte into the macrophage foam cell. T cells likewise encounter signals that cause them to elaborate inflammatory cytokines such as $\gamma$-interferon and lymphotoxin (tumor necrosis factor [TNF]- $\beta$ ) that in turn can stimulate macrophages as well as vascular endothelial cells and SMCs. As this inflammatory process continues, the activated leukocytes and intrinsic arterial cells can release fibrogenic mediators, including a variety of peptide growth factors that can promote replication of SMCs and contribute to elaboration by these cells of a dense extracellular matrix characteristic of the more advanced atherosclerosis lesion. Inflammatory processes not only promote initiation and evolution of atheroma, but also contribute decisively to precipitating acute thrombotic complications of atheroma. Most coronary arterial thrombi that cause fatal acute myocardial infarction arise because of a physical disruption of the atherosclerotic plaque (Cybulsky et al., 2001; Forstermann \& Munzel, 2006; Ishizuka et al., 1999; Lee et al., 2001; Libby et al., 2002; Quehenberger et al., 2000; Schneider et al., 2002).

\section{Endothelial dysfunction and diabetes}

The role of endothelial dysfunction in type 2 diabetes is more complicated than that for type 1. The effects of ageing, hyperlipidemia, hypertension and other factors add to the complexity of the problem. In contrast to patients with type 1 diabetes, endothelial dysfunction can also occur in patients with type 2 diabetes even when the patients have normal urinary albumin excretion. In fact, markers of endothelial dysfunction are often elevated years before any evidence of microangiopathy becomes evident (Gazis et al., 1999).

The insulin resistance syndrome encompasses a subnormal response to insulin-mediated glucose disposal and frequently elevated blood pressure, hyperlipidemia and dysfi binolysis, even without any clinically demonstrable alteration in plasma glucose concentrations (Steinberg et al., 1994). There is a growing body of evidence to suggest the coexistence of insulin resistance and endothelial dysfunction. Insulin-induced vasodilation, which is partially mediated by NO release, is impaired in obese individuals who do not have type 2 diabetes but whom display insulin resistance (Cleland et al., 2000).

Moreover, the obese state, a model of human insulin resistance, is associated with high levels of endothelin in plasma. Also blood concentrations of PAI-1 are high in patients with otherwise uncomplicated obesity (Calles-Escandón et al., 1996). Endothelial activation and acute-phase reaction correlate with insulin resistance and obesity in type 2 diabetic patients (Leinonen et al., 2003).

Abnormalities in vascular reactivity and biochemical markers of endothelial cell activation are present early in individuals at risk of developing type 2 diabetes. The vasodilatory responses to acetylcholine were reduced in healthy normoglycemic subjects who have first degree diabetic relatives. The plasma levels of endothelin-1 were significantly higher in subjects with impaired glucose tolerance and patients with type 2 diabetes without vascular 
complications compared with healthy normoglycemic subjects with no history of type 2 diabetes in a first-degree relative (Caballero ET AL., 1999). In addition there is a significant association between endothelial dysfunction and insulin resistance in young first degree relatives of DM subjects independent of the classic cardiovascular risk factors (Balletshofer ET AL., 2000).

In a case-cohort study, using the Monitoring of Trends and Determinants in Cardiovascular Disease (MONICA)/ Cooperative Research, men and women with elevated levels of sEselectin had a significantly increased risk of type 2 diabetes after multivariable adjustment. Hazard ratios (95\% CIs) comparing tertile extremes of sE-selectin were 2.63 (1.79-3.88) and 1.71 (1.07-2.75) for men and women, respectively. Elevated levels of sICAM-1 were also associated with an increased risk of type 2 diabetes; however, the association was not independent of other diabetes risk factors including E-selectin, while vWF was not associated with risk of type 2 diabetes (Thorand et al., 2006). A prospective, nested casecontrol study within the Nurses' Health Study, has found elevated E-selectin and ICAM-1 levels can predict incident diabetes in logistic regression models conditioned on matching criteria and adjusted for body mass index (BMI), family history of diabetes, smoking, diet score, alcohol intake, activity index and postmenopausal hormone use. Adjustment for waist circumference instead of BMI or further adjustment for baseline levels of C-reactive protein, fasting insulin, and $\mathrm{HbA} 1 \mathrm{c}$ or exclusion of cases diagnosed during the first 4 years of followup did not alter these associations (Meigs et al., 2004).

In the other hand, in diabetes, glycation, tissue oxidation and endothelial function are all abnormal and predisposing to microvascular complications but interrelationships are complex with glycation appearing most direct (Wen et al., 2002). The patients with microalbuminuria, unlike those without it, are characterized by longer course of diabetes, more pronounced lipid exchange disorder, more variable arterial pressure, higher pressure load index, elevated activity of lipid peroxidation (LP) processes and prominent disorder of NO-producing endothelial function. All improve with treatment (Ametov et al., 2005). The Endothelium-dependent vasodilation was impaired in the microalbuminuric patients compared with the normoalbuminuria patients and the healthy controls. Plasma PAI-1 and vWF levels increased in the microalbuminuric patients compared with the levels in the normoalbuminuric patients and in the healthy controls (Yu et al., 2005).

In addition, in type 2 diabetes mellitus as in type 1, increased calpain (calcium-dependent protease) activity in response to hyperglycemia may play a role in diabetic cardiovascular disease. Immunoprecipitation studies revealed that glucose induces loss of NO via a calpain-dependent decrease in the association of hsp90 with endothelial NOS. In addition, inhibition of calpain activity decreased endothelial cell surface expression of the proinflammatory adhesion molecules ICAM-1 and VCAM-1 during hyperglycemia (Stalker et al., 2003). Furthermore inhibition of PKC activity reduces leukocyte-endothelium interactions by suppressing surface expression of endothelial cell adhesion molecules in response to increased oxidative stress (Booth et al., 2002).

In diabetes associated with diabetic microangiopathy, compared with non diabetics, asymmetric dimethylarginine [ADMA]; an endogenous inhibitor of NOS, serum TNF-alpha and soluble TNF receptor I (sTNFR-I) has been assessed in a study which concludes that the serum sTNFR-I and VEGF levels were signifi cantly increased, but no difference in the serum TNF-alpha, sTNFR-II, and ADMA levels between uncomplicated diabetic patients and in non diabetics (Makino et al., 2005). Increased levels of vWF antigen, t-PA antigen and PAI-1 activity were seen in impaired glucose tolerance (IGT) and diabetics compared with 
the normal glucose tolerance (NGT). Tissue factor pathway inhibitor TFPI activity and thrombomodulin levels were increased in all elderly subjects, with positive association between $\mathrm{HbA}(1 \mathrm{c})$, TFPI activity and vWF antigen. Fasting blood glucose levels correlated with vWF antigen, t-PA antigen and PAI-1 activity, whereas urine albumin excretion correlated with TFPI activity, vWF antigen and PAI-1 activity. Serum insulin levels correlated strongly not only with vWF antigen and t-PA antigen but also with PAI-1 activity. This correlation did not change after further adjustment for serum glucose and $\mathrm{HbA}(1 \mathrm{c})$, which may suggest that in the elderly subjects, impaired fibrinolysis is probably associated with insulin resistance (Leurs et al., 2002). The above reflect a prothrombotic state associated with an insulin resistance state, an increased vWF release, raised sP-Sel and TNFalpha levels and, may be, low NO bioavailability, which could lead to a higher risk of development of thrombotic events in hypertensive diabetic patients (Ouvina et al., 2001).

Besides this, NADPH oxidase gene expression is increased in circulating lymphomonocytes from patients with DM, and this increased gene expression is dependent upon metabolic control. Hyperglycemia can mediate its adverse effects through the activation of protein kinase C. Recent study has shown an increase in membrane-associated PKC beta 2 activity in monocytes from patients with DM. This activity was reduced by $40 \%$ in the euglycemic condition (Avogaro et al., 2001). Further more patients with Type 2 diabetes with good residual C-peptide secretion are better protected from endothelial dysfunction that those with poor C-peptide secretion (Manzella et al., 2003).

\subsection{Hyperglycemia as the major causal factor in the development of endothelial dysfunction}

Clinical trials have identified hyperglycemia as the key determinant in the development of chronic diabetic complications. The formation of advanced glycation end products (AGEs) is an important biochemical abnormality accompanying diabetes mellitus and, likely inflammation in general. Although the mechanisms underlying this phenomenon are likely to be multi-factorial, recent in-vivo and in- vitro studies have indicated a crucial role of the diacylglycerol (DAG)-protein kinase $C$ (PKC) pathway in mediating this phenomenon. PKC may have multiple adverse effects on vascular function, including the activation of superoxide-producing enzymes such as the nicotinamide adenine dinicleotide phosphate (NADPH) oxidase as well as increased expression of a dysfunctional, superoxide-producing, uncoupled endothelial nitric oxide synthase (NOS III). PKC-mediated superoxide production may inactivate NO derived from endothelial NOS III, and may inhibit the activity and/or expression of the NO downstream target, the soluble guanylyl cyclase. The effects of AGEs on vessel wall homeostasis may account for the rapidly progressive atherosclerosis associated with diabetes. Driven by hyperglycemia and oxidant stress, AGEs form to a greatly accelerated degree in diabetes. Within the vessel wall, collagen-linked AGEs may "trap" plasma proteins, quench NO activity and interact with specific receptors to modulate a large number of cellular properties. On plasma low density lipoproteins (LDL), AGEs initiate oxidative reactions that promote the formation of oxidized LDL. The interaction of AGEs with endothelial, as well as with other cells accumulating within the atherosclerotic plaque, such as mononuclear phagocytes and smooth muscle cells, provides a mechanism to augment vascular dysfunction. Specifically, the interaction of AGEs with vessel wall component increases vascular permeability, the expression of procoagulant activity and the generation of reactive oxygen species, resulting in increased endothelial expression of endothelial 
leukocyte adhesion molecules (Farhangkhoee et al., 2006), while acute hyperglycemia and hyperinsulinemia induced vasodilatation is not accompanied by changes in microvascular permeability or endothelial markers. The effects of acute glycemia on plasma nitric oxide (NO; nitrite plus nitrate) levels, $\mathrm{Cu}-\mathrm{Zn}$ Superoxide dismutase (Cu-Zn SOD) activity and thiobarbituric acid-reactive substances (TBARS) levels were studied in age-matched female subjects before and two hours after glucose loading. Plasma NO levels were significantly higher in subjects with diabetic glucose tolerance (DGT) than in subjects with normal glucose tolerance $(p<0.001)$ and impaired glucose tolerance $($ IGT $)(p<0.05)$ at baseline. TBARS levels were significantly elevated in subjects with DGT and IGT $(\mathrm{p}<$ 0.001 and $\mathrm{p}<0.001)$. Cu-Zn SOD activities were significantly increased in subjects with NGT, and were significantly decreased in subjects with IGT and DGT ( $p<0.001$ and $p<$ 0.001) after glucose loading; suggest that NO availability was decreased when the blood glucose levels were only moderately elevated above normal levels. This might be related with the enhanced oxidative stress (Konukoglu et al., 2003). Other studies examined the effect of acute hyperglycemia on endothelium-dependent vasodilation in patients with DM or impaired glucose metabolism in- vivo by plethysmography. The vasodilatory response to acetylcholine at infusion rates of 7.5, 15, and $30 \mathrm{microg} / \mathrm{min}$ was studied in the fasting state and at two levels of hyperglycemia, which were achieved by the infusion of glucose, insulin and somatostatin. The vasodilatory response to acetylcholine was measured by calculating the forearm blood fl ow ratio (FBFR), defined as the measured forearm blood flow at a specific acetylcholine infusion rate divided by the baseline forearm blood flow without acetylcholine infusion. The induction of hyperglycemia resulted in a significant reduction in FBFR for all rates of acetylcholine infusion and suggests the importance of hyperglycemia in the development of endothelial dysfunction observed in patients with DM or impaired glucose metabolism (Bhargava et al., 2003).

\section{Endothelial dysfunction and therapeutic intervention}

Several pharmacological interventions have been used to improve endothelial function in patients with type 2 diabetes mellitus in this part of the chapter we will mention the most important issues.

\subsection{Antidiabetics}

\subsubsection{Metformin}

Metformin is an oral anti-hyperglycaemic agent which enhances insulin sensitivity and lowers hepatic glucose output (Hundal \& Inzucchi, 2003). In obese patients with T2DM, metformin is currently the drug of first choice due to its bilateral effect on glycaemic regulation and cardiovascular protection (Inzucchi 2002; (Union Kingdom Prospective Diabetes Study, [UKPDS], 1998 (UKPDS,1998). However, obese and non-obese patients with T2DM experience a similar cardiovascular risk (Adlerberth et al., 1998; Manson et al., 1991) and the use of metformin even in the non-obese patients with T2DM might be beneficial as well.

In predominantly obese patients with $\mathrm{T} 2 \mathrm{DM}$, metformin has previously been shown to decrease levels of vWf, sVCAM-1, ADMA, methylglyoxal (i.e. a major precursor in the formation of AGE) and albuminuria (Abbasi et al., 2004; Asagami et al., 2002; AmadorLicona et al., 2000; Beisswenger et al.,1999; De Jager et al., 2005; Nagi \& Yudkin., 1993) and either decrease or having no significant effect (Abbasi et al., 2004; Asagami et al., 2002; Chu 
et al., 2002; De Jager et al., 2005; Natali et al., 2004; Testa et al., 1996) on circulating levels of CRP, TNF-a, PAI-1-ag, t-PA-ag, sICAM-1 and sE-selectin.

Recent in vitro studies have suggested that metformin activates the intracellular 'fuelsensor', i.e. the AMP activated kinase (AMPK). The activated AMPK, in turn, inhibits the TNF-a-induced activation of the nuclear transcription factor, NF-kB, and hereby the NFkBinduced gene expression of sICAM-1, sVCAM and sE-selectin (Hattori et al., 2006; Isoda et al., 2006). In the other hand, in a recent study comparing metformin versus repaglinide, a decrease was observed in several CVD biomarkers, may be explained by actions of metformin via the pathway of AMPK, TNF-a and NF-kB. The changes from first-period baseline in the levels of TNF-a were not significantly different from zero during either of the two treatments.

Therefore, besides AMPK other, yet unknown, mechanisms (promoting, inhibitory and/or feedback) might contribute to the effect of metformin as well as repaglinide on CVD biomarkers. This is also underscored by the attenuating effect of metabolic variables on the treatment effects on several CVD biomarkers in that study

\subsubsection{Thiazolidinediones}

Thiazolidinediones enhances insulin-mediated glucose uptake into insulin target tissues, through activation of peroxisome proliferator-activated receptor (PPAR) (Mudaliar \& Henry, 2001). They have direct effects on adipose tissue by suppression TNF and, possibly, leptin expression; suppress lipolysis and thus decrease plasma free fatty acid concentrations and increase plasma adiponectin levels (Hauner, 2002) and exert direct effects on insulinmediated glucose transport in skeletal muscle and the heart (Bishop-Bailey, 2000).

Thiazolidinedione administration reverses insulin resistance and many components of the metabolic syndrome. Treatment is generally associated with increased HDL cholesterol levels; decreased blood pressure, plasma triglyceride levels, small dense LDL cholesterol particles, PAI-1 levels and albumin excretion rates; in addition to decreased glucose levels and reduced hemoglobin A1C levels (Freed et al., 2002). PPAR ligands also improve endothelial function (Dandona \& Aljada, 2004). Several studies have demonstrated improvements in brachial artery reactivity in patients with diabetes. (Caballero et al., 2003).

Rosiglitazone, improves coronary artery endothelial function in patients with insulin resistances who have no traditional risk factors for atherosclerosis as well as no impaired glucose tolerance or diabetes (Quiñones et al., 2002). With an increase in insulin sensitivity and a drop in fasting insulin and free fatty acid levels, thiazolidinediones in combination with hormone therapy (HT) in postmenopausal women is, however, have shown in study to attenuates endothelial function (Honisett et al., 2004).

The mechanisms by which thiazolidinediones improve endothelial-dependent blood $\mathrm{fl}$ ow are unknown, but likely involve several effects. First, as described above; it has an important anti-inflammatory effects that involve decreasing circulating adipokines levels (eg, TNF, PAI-1, leptin), which are reflected by reduced high-sensitivity C-reactive protein levels; increasing adiponectin levels; decreasing vascular expression of adhesion molecules (Wakino et al., 2002). Second, insulin is a vasodilator stimulating expression of eNOS through the phosphatidylinositol 3-kinase (PI3K) pathway (Zeng et al., 2000). This effect of insulin is blunted in patients with insulin resistance (Kuboki et al., 2000). PPAR- is expressed in endothelial cells, and its ligands have been reported to enhance NO production, possibly by stimulating the PI3K pathway and hence expression of eNOS (Kim et al., 2002). Third, PPAR- ligands improve several components of the metabolic syndrome 
that could adversely affect endothelial function, including low HDL cholesterol levels, high triglyceride and free fatty acid levels, hypertension and carbohydrate intolerance. PPARligands also decrease oxidative stress and thus are able to improve the vascular balance between NO and vasoconstrictors (Bagi et al., 2004).

Rosiglitazone administration for 12 weeks was shown to improve insulin sensitivity and decrease asymmetric dimethylarginine levels. An endogenous inhibitor of NOS, is associated with reduced NO-mediated vasodilation and enhanced adherence of mononuclear cells to the endothelium (Stuhlinger et al., 2002). In recently performed a double-blind crossover trial of 12 patients with recently diagnosed type 2 diabetes concludes that insulin resistance is a major contributor toward endothelial dysfunction in type 2 diabetes; both endothelial dysfunction and insulin resistance are amenable to treatment by rosiglitazone (Pistrosch et al., 2005).

Recently studies have shown that Rosiglitazone ameliorated glomerular hyperfiltration in early type 2 diabetes, improved NO bioavailability and lessened renal end-organ damage in type 2 diabetes with microalbuminuria (Pistrosch et al., 2004) and Pioglitazone improves endothelial dysfunction independently from the observed benefits on insulin sensitivity and beta-cell function in patients with newly diagnosed type 2 diabetes and CAD and may exerts additional effects on endothelial function beyond metabolic control (Forst et al., 2005). Furthermore the GATE study may provide the rationale and impetus for the aggressive treatment of insulin-resistant patients with glitazone therapy (Hubacek et al., 2004).

Recently a study was published that used the addition of pioglitazone and ramipril to intensive insulin therapy in Type 2 diabetic patients that which showed that pioglitazone improves vascular dysfunction by different mechanisms.

In this study, they demonstrated that the addition of either the insulin sensitizer pioglitazone or the ACE-blocking agent ramipril further improves vascular dysfunction and markers of inflammation independent of glycemic control. their data indicate that pioglitazone primarily enhances endothelial-mediated, whereas ramipril augments endothelial-independent, vasodilation. These different vascular effects, combined with the observation that pioglitazone increases the vasodilator adiponectin concentration, while ramipril reduces the vasoconstrictor endothelin-1 levels, suggest that different and complementary mechanisms underlie the observed improvements in vascular reactivity. In agreement with previous studies, pioglitazone therapy also was accompanied by a reduction in plasma fatty acids and triglyceride concentrations, both of which may play a role in the correction of vascular dysfunction (Natali et al., 2004; Pfutzner et al., 2005; Wajcberg et al., 2007) [120-122]. Previous studies (Natali et al., 2004; Pfutzner et al., 2005) also have shown that pioglitazone can improve endothelial dysfunction independent of changes in blood glucose levels. Thus, it is likely that the beneficial effects of TZDs on vascular function are mediated by 1) direct effects on the vascular endothelium, 2) improved glycemic control, and 3) enhanced insulin-mediated glucose metabolism. Pioglitazone did not improve endothelial- independent vasodilation beyond that observed with intensive insulin therapy alone.

\subsubsection{Meglitinides}

Recently the repaglinide administration, showed that it improves brachial reactivity and declines oxidative stress indexes. in vitro through good control of postprandial glucose levels, in agreement with previous data (Ceriello, 2004; Gomes et al., 2004; Gross et al., 2003). 
In addition, the relationship between changes in 2-h plasmaglucose levels and brachial reactivity is independent of the main metabolic parameters but is dependent on the TBARS and TEAC levels. The latter data, according to a previous study showing that endothelial dysfunction is present in the postprandial state in type 2 diabetic patients (Ceriello et al., 2004), they support the hypothesis that 2-h plasma glucose levels are the main factor determining oxidative stress and endothelial dysfunction and that a tight control of postprandial glucose excursion-as those found after repaglinide-is a key point for preventing endothelial dysfunction and macroangiopathy (Manzella et al., 2005).

Furthermore, because the modulation of vascular tone is mediated by NO and endotheliumderived hyperpolarizing factor (EDHF), and because the role of EDHF in modulating vascular smooth muscle contraction is mediated by $\mathrm{KCa}$ channels on vascular smooth muscle (Georgescu et al., 2001; Inokuchi et al., 2003), While Nateglinide an oral antidiabetic insulinotropic agent neither improved nor impaired myocardial blood flow in Type 2 diabetic patients (Bengel et al., 2005).

\subsection{4 $\alpha$-glucosidase inhibitors}

\subsubsection{Acarbose}

Acarbose inhibits enzymes (glycoside hydrolases) needed to digest carbohydrates, to be specific, alpha-glucosidase enzymes in the brush border of the small intestines and pancreatic alpha-amylase. Pancreatic alpha-amylase hydrolyzes complex starches to oligosaccharides in the lumen of the small intestine, whereas the membrane-bound intestinal alpha-glucosidases hydrolyze oligosaccharides, trisaccharides, and disaccharides to glucose and other monosaccharides in the small intestine. Inhibition of these enzyme systems reduces the rate of digestion of complex carbohydrates.

There is a randomized Crossover Study with Acarbose, that shows the effects of a single administration of acarbose on postprandial glucose excursion and endothelial dysfunction in type 2 diabetic patients. In this study the authors hypothesize that acarbose might reduce macrovascular complication by avoiding endothelial injury in postprandial hyperglycemic status (Shimabukuro et al., 2006)].

A potential mechanism by which postprandial hyperglycemia impairs endothelial function is the generation of reactive oxygen species (ROS) (Sheetz \& King, 2002). (Yano et al., 2004) reported that a short-time exposure $(3 \mathrm{~h})$ to $25 \mathrm{mmol} /$ liter glucose increased intracellular ROS generation in cultured bovine aortic endothelial cells. Previously has been reported that nateglinide, a phenylalanine-derived insulin secretagogue, could also improve postchallenge endothelial function in type 2 diabetic patients (Shimabukuro et al., 2004).

Collectively, postprandial endothelial function could be improved by an intervention to reduce postprandial glucose peak at least in part. (Vallejo et al., 2005) reported that acetylcholine-induced endothelium-dependent relaxations were impaired in aortic and mesenteric vessels isolated from streptozotocin-induced diabetic rats, and such endothelial dysfunction was improved either with suppression of blood glucose levels by acarbose or with ROS suppression by superoxide dismutase. Taken together, it was still possible that suppression of postchallenge hyperglycemia by acarbose decreased generation of ROS and the ROS-mediated impairment of endothelial function, although we could not detect changes of urinary 8-epi-prostaglandin-F2, one reliable marker of whole-body oxygen stress, during the test meal loading. Previous studies showed that insulin can induce either vasodilation by 
increasing NOx levels or vasoconstriction by stimulating endothelin-1 levels (Piatti et al., 2003) and the net balance between vasodilator and vasoconstrictor effects of insulin is altered in diabetic patients in favor of a relative vasoconstriction (Cardillo et al., 2002). In the study of (Shimabukuro et al., 2006), there were no significant differences in plasma NOx and endothelin-1 levels before and after meal ingestion in control and diabetic subjects. Because plasma levels of endothelin- 1 may not truly reflect the activity of endothelin- 1 and endothelin receptor subtype A (ETA)-dependent mechanism could be involved in vascular derangements of diabetic condition, additional future studies need to be done.

\subsubsection{Miglitol}

Miglitol has been launched as an a-GI, which possesses particular pharmacokinetics. Miglitol is absorbed rapidly and almost completely from the small intestine after oral administration (Ahr et al., 1997). Thus, it can strongly suppress the elevation of blood sugar levels shortly after a meal while causing relatively fewer side-effects in the digestive system such as abdominal bloating and diarrhea. The administration of miglitol has been demonstrated to suppress the progression of atherosclerosis associated with controlling fluctuations of blood sugar in apolipoprotein E knockout mice (Mita et al., 2007).

Recently (Makoto et al., 2010), reported the post-prandial effects of a single administration of miglitol and voglibose on endothelial function and changing levels of glucose, insulin, lipids, glucagon-like peptide (GLP)-1, and gastric inhibitory polypeptide (GIP) that were compared after a standard meal loading in 11 diabetic patients with $\mathrm{CAD}$, using a placebo controlled cross-over design. They showed the changing levels of glucose, insulin and triglycerides at $60 \mathrm{~min}$ were significantly lower in the miglitol group than in the voglibose and placebo groups (all $\mathrm{P}<0.01$ ). GLP-1 levels that were significantly higher at $120 \mathrm{~min}$ $(\mathrm{P}<0.05)$ and GIP levels were significantly lower at $30 \mathrm{~min}$ and $60 \mathrm{~min}(\mathrm{P}<0.05)$ in the miglitol group compared to other treatments. The reactive hyperemia duration at $120 \mathrm{~min}$ was significantly maintained in the miglitol group compared to the other groups.

The precise mechanisms are still unidentified, but negative correlations between endothelial function and the indices of changing of post-prandial glucose levels were demonstrated. A previous study also reported the association between post-prandial endothelial function and post-prandial glucose levels (Shimabukuro et al., 2006). In addition, swings in glucose levels affect monocyte adhesion to the endothelium in animal models (Mita et al., 2007) and oscillating glucose levels cause much deleterious impairment on endothelial function rather than constant high glucose (Ceriello et al., 2008). Therefore, post-prandial endothelial function could, in part, be improved by amelioration of post-prandial glucose levels by administration of miglitol.

\section{Insulin therapy}

The UK Prospective Diabetes Study (UKPDS) showed that intensive blood glucose control with insulin or sulfonylureas, both of which significantly increase circulating free insulin concentrations, retards the development of microvascular complications. The incidence of myocardial infarction decreased by $16 \%$, which was almost statistically significant $(\mathrm{P}=.052)$. Neither insulin nor sulfonylureas had adverse effects on cardiovascular outcome (Union Kingdom Prospective Diabetes Study, [UKPDS], 1998 (UKPDS, 1998).

Considering this, an "in vivo" study was reported (Vehkavaara et al., 2000), in which the endothelial function was measured in 18 type 2 diabetic patients previously treated with 
metformin (1000 mg BID, n514; $500 \mathrm{mg}$ BID, n54) before and 6 months after combination therapy with bedtime human isophane insulin and metformin (effect of insulin therapy). A control group of 27 normal subjects was studied to determine whether endothelial function was abnormal in the type 2 diabetic patients.

In this study a total of 75 in vivo endothelial function tests (intrabrachial artery infusions of endothelium-dependent [acetylcholine] and -independent [sodium nitroprusside] vasoactive agents) were performed in 18 type 2 diabetic patients and 27 matched normal subjects. These tests were performed before and 6 months after combination therapy with insulin and metformin and before and 6 months after metformin therapy only. Before insulin therapy, blood flow responses to acetylcholine were significantly blunted in type 2 diabetic patients compared with normal subjects. During insulin therapy, the acetylcholine response increased by $44 \%(\mathrm{P}<0.05)$. Insulin therapy also significantly increased the blood flow responses to both low and high doses of sodium nitroprusside. They conclude that insulin therapy improves endothelium-dependent and -independent vasodilatation. These data support the idea that insulin therapy has beneficial rather than harmful effects on vascular function.

In the Diabetes Mellitus Insulin Glucose Infusion in Acute Myocardial Infarction (DIGAMI) study, patients with an acute myocardial infarction, who received insulin acutely and chronically, had a $28 \%$ reduction in mortality rate compared with those of patients who continued their existing therapies Coronary endothelial dysfunction, defined as impaired vasodilatory response to intracoronary infusion of acetylcholine (ACh), is an independent predictor of vascular events even after adjustment for traditional cardiovascular risk factors (Schachinger et al., 2000; Suwaidi et al., 2000). Recently, these findings were extended to measurements performed across the forearm vascular bed (Heitzer et al., 2001; Perticone et al., 2001).

Regarding insulin, acute studies have shown that a physiological increase in the circulating insulin concentration potentiates ACh-induced but not sodium nitroprusside (SNP)-induced vasodilatation (Rask-Madsen et al., 2001; Taddei et al., 1995). In studies addressing effects of long-term insulin therapy on endothelial function, we have previously shown that endothelium-dependent and endothelium independent blood flow in forearm resistance vessels improves during 6 months of combination therapy with bedtime neutral protamine Hagedorn $(\mathrm{NPH})$ insulin and metformin, while continuation of long-term metformin therapy had no effect on vascular function (Vehkavaara et al., 2000). In another study of patients with type 2 diabetes, 2 months of insulin therapy tended $(\mathrm{P}<0.09)$ to increase the blood flow response to ACh and restored the ability of insulin to acutely potentiate AChinduced vasodilatation (Rask-Madsen et al., 2001).

Insulin glargine is a long-acting insulin analogue. Compared with regular human insulin in vitro, insulin glargine was, in one study, reported to have a 6.5-fold higher affinity for insulinlike growth factor 1 (IGF-1) receptors in transfected baby hamster kidney cells (Kurtzhals et al., 2000). In contrast to these results, a recent study found equivalent binding of insulin glargine and regular human insulin to insulin and IGF-1 receptors in skeletal muscle cells (Ciaraldi et al., 2001). IGF-1 is a potent stimulator of blood flow (Pendergrass et al., 1998). It is therefore not self-evident that effects of glargine on vascular function are similar to those of human insulin.

(Vehkavaara \& Yki-Järvinen, 2004), determined the effects of 3.5 years of addition of insulin glargine to previous metformin therapy on in vivo endothelial function in patients with type 
2 diabetes. The data were compared with data from a group of normal subjects. A total of 49 in vivo endothelial function tests, intrabrachial artery infusions of endothelium dependent (acetylcholine [ACh]) and endothelium-independent (sodium nitroprusside [SNP]) vasoactive agents, were performed in 11 patients with type 2 diabetes and 16 matched normal subjects. The tests in the type 2 diabetic patients were performed before and after 6 months and 3.5 years of combination therapy with insulin glargine and metformin. The study conclude that insulin glargine therapy improves endothelium-dependent and endothelium-independent vasodilatation. These data support the idea that long-term insulin therapy has beneficial rather than harmful effects on vascular function in type 2 diabetes.

\section{Inhibition of renin angiotensin pathway}

Angiotensin II has several pro-oxidative effects on the vasculature, decreasing $\mathrm{NO}$ bioavailability and resulting in vascular injury. ACE inhibitors are known to improve endothelial dysfunction, but the ability of angiotensin receptor blockers to improve endothelial dysfunction is less clear (Mancini et al., 1996). Both drug classes consistently prevent coronary artery (particularly in the case of ACE inhibitors), stroke, and diabetic microvascular complications of nephropathy and retinopathy (McFarlane et al., 2003).

Inhibition of the renin-angiotensin system is associated with reduced incidence of new-onset diabetes. In the Heart Outcomes Prevention Evaluation (HOPE) study) (Yusuf et al., 2001), the incidence of diabetes was 32\% lower in the ramipril-treated group than in the placebo group. In the Losartan Intervention for Endpoint reduction in hypertension (LIFE) study (Dahlof et al., 2002), losartan was associated with 25\% less new-onset diabetes compared with atenolol. The mechanisms responsible for the reduced incidence of diabetes observed during these trials are unknown, although possible mechanisms include increased plasma bradykinin levels, which improves insulin-mediated glucose uptake (Duka et al., 2001), improved endothelial function, increased vascular $\mathrm{NO}$ activity and reduced vascular inflammation.

Moreover, In view of the pathogenetic role of the imbalance between angiotensin II and NO in target-organ damage, it is a logical approach to target the renin-angiotensin system (RAS). Considering this, it has been observed that ACE inhibitors prevent the formation of angiotensin II from angiotensin I, whereas the angiotensin II receptor blockers (ARBs) specifically prevent the binding of angiotensin II to type 1 receptors (Burnier, 2001).

ACE inhibitors lead to accumulation of bradykinin, known to improve endothelial function, whereas ARBs elicit stimulation of the angiotensin II AT2 receptors and modulate peroxisome proliferator-activated receptor-receptors.

The clinical relevance of these additional effects of ACE inhibitors and ARBs is controversial. So far, the effects of ACE inhibitors and ARBs have been examined mainly in the peripheral circulation. Although small sample sizes have been used, significant improvement of endothelial function has been observed for both compounds used in the current trial.

Ramipril significantly improved renal endothelial function in normotensive, normoalbuminuric men with type 1 diabetes (Komerset al., 2000), and telmisartan increased endothelial function in treatment-naive hypertensive patients (Svolis et al., 2002). Recently, (Schmieder, 2007), reported the results head-to head comparisons examining the effects of RAS blockade on renal endothelial function in patients with type 2 diabetes and hypertension, who are known to have a very high risk of cardiovascular and renal 
morbidity (Delles et al., 2002; Schmieder, 2005). He studied in a multicenter, prospective, double-blind, forced-titration, randomized study, 96 patients with type 2 diabetes, hypertension, glomerular filtration rate $80 \mathrm{ml} / \mathrm{min}$, and normo-or microalbuminuria were treated once daily with $40 / 80 \mathrm{mg}$ telmisartan or 5/10 $\mathrm{mg}$ ramipril for 9 weeks. He concluded that in patients with type 2 diabetes, telmisartan and ramipril both increased NO activity of the renal endothelium significantly, which in turn may support the preservation of cardiovascular and renal function.

\section{Statin and endothelial dysfunction}

Several clinical trials have demonstrated that statin treatment not only reduces serum cholesterol levels in hypercholesterolemic patients, but also substantially decreases the risk of cardiovascular disease (Shepherd et al., 1995). In current clinical use, statins can reduce LDL cholesterol levels by an average of $20 \%-35 \%$, with a corresponding $30 \%-35 \%$ reduction in major cardiovascular outcomes. Decreases in serum cholesterol levels could account for the observed risk reduction, since LDL cholesterol has a strong, well documented association with cardiovascular risk, and since plasma LDL apheresis has been shown to improve both endothelium-dependent vasodilation and cardiovascular risk in hypercholesterolemic patients (Tamai et al., 1997). Several studies, however, have shown that improvements in endothelial function can occur before reductions in serum cholesterol levels. These acute effects are in agreement with other studies that have reported improvements in endothelial function after statin administration that do not correlate with reductions in serum LDL cholesterol levels, and it has been observed that statins can decrease high-sensitivity C-reactive protein levels by $30 \%-40 \%$, independent of their cholesterol lowering capacities (Ansell et al., 2003).

\subsection{Rosuvastatin}

In this context, the Justification for the Use of Statins in Prevention: an Intervention Trial Evaluating Rosuvastatin (JUPITER) Study (Ridker et al., 2008), that randomly assigned 17,802 apparently healthy men and women with low-density lipoprotein (LDL) cholesterol levels of less than $130 \mathrm{mg}$ per deciliter $(3.4 \mathrm{mmol}$ per liter) and high-sensitivity C-reactive protein levels of $2.0 \mathrm{mg}$ per liter or higher to rosuvastatin, $20 \mathrm{mg}$ daily, or placebo and followed them for the occurrence of the combined primary end point of myocardial infarction, stroke, arterial revascularization, hospitalization for unstable angina, or death from cardiovascular causes. The trial was stopped after a median follow-up of 1.9 years (maximum, 5.0). Rosuvastatin reduced LDL cholesterol levels by $50 \%$ and high-sensitivity C-reactive protein levels by $37 \%$.

The rates of the primary end point were 0.77 and 1.36 per 100 person-years of follow-up in the rosuvastatin and placebo groups, respectively (hazard ratio for rosuvastatin, $0.5695 \%$ confidence interval $[\mathrm{CI}], 0.46$ to $0.69 ; \mathrm{P}<0.00001$ ), with corresponding rates of 0.17 and 0.37 for myocardial infarction (hazard ratio, $0.46 ; 95 \% \mathrm{CI}, 0.30$ to $0.70 ; \mathrm{P}=0.0002$ ), 0.18 and 0.34 for stroke (hazard ratio, $0.52 ; 95 \% \mathrm{CI}, 0.34$ to $0.79 ; \mathrm{P}=0.002$ ), 0.41 and 0.77 for revascularization or unstable angina (hazard ratio, 0.53 ; $95 \% \mathrm{CI}, 0.40$ to $0.70 ; \mathrm{P}<0.00001$ ), 0.45 and 0.85 for the combined end point of myocardial infarction, stroke, or death from cardiovascular causes (hazard ratio, $0.53 ; 95 \% \mathrm{CI}, 0.40$ to $0.69 ; \mathrm{P}<0.00001$ ), and 1.00 and 1.25 for death from any cause (hazard ratio, $0.80 ; 95 \% \mathrm{CI}, 0.67$ to $0.97 ; \mathrm{P}=0.02$ ). The conclusion of 
this trial is that in apparently healthy persons without hyperlipidemia but with elevated high-sensitivity C-reactive protein levels, rosuvastatin significantly reduced the incidence of major cardiovascular events.

\subsection{Atorvastatin}

Undoubtedly the most important study to demonstrate the pleiotropic effect of atorvastatin has been The Reversal of Atherosclerosis with Aggressive Lipid Lowering (REVERSAL) study (Nicholls et al., 2006), this clinical trial was carried out to determine the influence of increasing body mass index (BMI) on plasma lipids, C-reactive protein, plaque burden as determined by intravascular ultrasound, and the serial change in these parameters with a moderate or intensive lipid-lowering strategy. In this clinical trial patients were randomized to receive an intensive lipid-lowering strategy with 80 $\mathrm{mg}$ /day of atorvastatin and a pravastatin placebo or a moderate lipid-lowering strategy with $40 \mathrm{mg} /$ day of pravastatin and an atorvastatin placebo. Treatments were administered for an 18-month period. Patients with a higher BMI were younger, more likely to be women, and had a greater prevalence of hypertension, diabetes, and the metabolic syndrome. Although a higher BMI was associated with a lower high-density lipoprotein level and higher triglyceride and C-reactive protein levels, there was no apparent influence of BMI on plaque burden. However, with the intensive lipid-lowering strategy, a greater BMI was associated with a lower proportionate decrease in lowdensity lipoprotein $(49.1 \pm 21.4 \%$ vs $43.0 \pm 22.4 \%$, p < 0.008$)$ and a greater proportionate decrease in C-reactive protein $(39.7 \%$ vs $33.3 \%$, p <0.04). Further, although moderate and intensive lipid-lowering strategies halted plaque progression in subjects with a lower BMI (median progression rates $+1.5 \%$ and $+1.2 \%$, respectively), a significant effect on plaque progression rates was seen only with adoption of an intensive lipid lowering strategy in the most obese subjects (median progression rate $-1.88 \%$ vs $+6.5 \%$ with the moderate lipid-lowering strategy, $\mathrm{p}<0.01$ ). In conclusion, plaque progression in obese patients is attenuated using an intensive, but not moderate, lipid-lowering strategy. These results highlight the need for aggressive risk factor modification and a decrease in vascular inflammation in obese patients.

These findings provide further evidence in support of the concept that statins possess significant nonlipid-lowering properties in vivo (Takemoto \& Liao, 2001). It is likely that statins inhibit the inflammatory cascade by multiple mechanisms. Statins decrease lowdensity lipoprotein (Schectman et al., 2004) and oxidative stress (Stoll et al., 2004), which are key promoters of inflammatory events. In addition, it is becoming increasingly recognized that statins may exert direct anti-inflammatory effects at the level of the arterial wall. Inhibition of isoprenylation by statins results in a decrease in the activation and nuclear translocation of the transcription factor, nuclear factor $\mathrm{kB}$ (Inoue et al., 2002). Nuclear factor $\mathrm{kB}$ plays a central role in directing inflammatory events. Similarly, statins inhibit the modification of proteins by myeloperoxidase-catalyzed reactive nitrogen species (Shishehbor et al., 2003). These species have been demonstrated to promote multiple inflammatory pathways. In support of this observation, atorvastatin therapy has been shown to decrease systemic levels of nitrotyrosine, a major product of myeloperoxidase-catalyzed pathways (Shishehbor et al., 2003). The ability of statins to modulate each of these inflammatory pathways in obese patients in vivo remains to be clarified. 


\section{The phosphodiesterase-5 inhibitors}

PDE-5 inhibitors cause an accumulation of NO-driven cGMP and subsequent vasodilatation in the corpus cavernosum and in pulmonary vasculature, therefore pharmacological PDE-5 inhibition has become a widely used treatment for erectile dysfunction (Shabsigh, 2004) and pulmonary arterial hypertension (Galiè et al., 2005). Effects of the different PDE-5 inhibitors on vasomotor function have also been described (Schäfer et al., 2008; Teixeira et al., 2006). In recent years it has been demonstrated, that not only the vascular wall, but also myocardial tissue contains PDE-5 (Giordano et al., 2001; Senzaki et al., 2001), 183] and there has been considerable interest in the role of the NO-cGMP-protein kinase G (PKG) pathway in cardioprotection (Kukreja et al., 2004). Recent studies reported considerable myocardial protection (Salloum et al., 2006) and improvement of endothelial dysfunction (Gori et al., 2005) after ischaemia/reperfusion with pharmacological PDE-5 inhibition, which were mediated by cGMP-induced opening of ATP-sensitive $\mathrm{K}+$ channels.

\subsection{Sildenafil citrate}

Sildenafil citrate, a potent PDE-5 inhibitor has been reported to improve the impaired endothelial function in smokers (Vlachopoulos et al., 2004), in patients with coronary artery disease (Halcox et al., 2002) and most recently in the setting of experimental diabetes (Schäfer et al., 2008). In addition, intracellular cGMP accumulation has been shown to reduce oxidative tissue injury in conditions associated with increased free radical release and oxidative stress (Abdollah et al., 2003) and even in diabetes mellitus (Milani et al., 2005).

Moreover, sildenafil citrate has been shown to display beneficial cardiovascular effects in patients with congestive heart failure and pulmonary hypertension, suggesting that it may have other systemic benefits involving the endothelium (Galie` et al., 2005). Administration of sildenafil citrate in both humans and animals offers protection against ischemic phenomena and it reduces the possibility of myocardial infarction after inducing ischemia (Bremer et al., 2005). There is little data regarding the long term use of PDE-5 and the effects of this on different organs. However, there is evidence that sildenafil citrate may be useful as an additional pharmacological strategy to deal with endothelial dysfunction in individuals with a high risk of developing CAD, as is the case of diabetic patients.

We reported recently the results of a double-blind, randomized, controlled trial in 40 male patients, age 35-50, with type 2 diabetes. Subjects received sildenafil citrate $50 \mathrm{mg}$ daily $(\mathrm{n}=$ $20)$ or placebo $(n=20)$ for 30 days. Levels of hs-CRP, microalbuminuria, homocysteine, A1c and erectile function were measured at baseline and to the end of the study. We found that men who received sildenafil citrate displayed a significant decrease in the microalbuminuria concentrations $(\mathrm{p}<0.01)$ versus baseline, $(\mathrm{p}=0.02)$ versus placebo and A1c $(\mathrm{p}<0.01)$ versus baseline, $(p=0.01)$ versus placebo (Grover-Páez et al., 2007).

Vardenafil and Tadalafil have also shown beneficial effects on endothelial function in different clinical trials (Schäfer et al., 2008).

\section{Other therapies}

Other therapies such as the use of antioxidants like vitamin E (Economides et al., 2005; Paolisso et al., 2003), coenzyme Q (Hamilton et al., 2009), folic acid (Oostrom et al., 2009) and allopurinol (Butle et al., 2000, have also demonstrated in several clinical trials some benefits 
on endothelial function, however more evidence is required to recommend these treatment strategies as prevention of endothelial damage in patients with type 2 diabetes mellitus.

\section{Conclusion}

Since endothelial dysfunction is the fundamental substrate for atherosclerosis and cardiovascular disease in patients with type 2 diabetes mellitus, it is imperative to study integrally to the diabetic patient taking into account both, the clinical manifestations, and the inflammation markers like the hsCRP, homocysteine, microalbuminuria, as the most important.

It is therefore of interest to the clinician to know which are the current treatment strategies that have demonstrated a real benefit to decrease the endothelial damage or delay it, like the use of ACEIs, ARBs, statins, folic acid, 5-PDF inhibitors, antioxidants, among others and include them as part of the comprehensive treatment of diabetic patients in addition to giving up the harmful habits known such as physical inactivity and smoking.

\section{References}

Abaci A, Oguzhan A, Kahraman S, Eryol NK, Unal S, Arinc H, Ergin A: Effect of diabetes mellitus on formation of coronary collateral vessels. Circulation 1999; 99(17):2239224290.

Abbasi F, Chu JW, McLaughlin T, Lamendola C, Leary ET \& Reaven GM. Effect of metformin treatment on multiple cardiovascular disease risk factors in patients with type 2 diabetes mellitus. Metabolism 2004;53: 159-164.

Abdollahi M, Fooladian F, Emami B, Zafari K, Bahreini-Moghadam A. Protection by sildenafil and theophylline of lead acetate induced oxidative stress in rat submandibular gland and saliva. Hum Exp Toxicol 2003; 22: 587-592.

Adlerberth AM, Rosengren A \& Wilhelmsen L. Diabetes and long term risk of mortality from coronary and other causes in middle aged Swedish men. A general population study. Diabetes Care 1998; 21:539-545.

Ahr HJ, Boberg M, Brendel E, Krause HP, Steinke W. Pharmacokinetics of miglitol. Absorption, distribution, metabolism, and excretion following administration to rats, dogs, and man. Arzneimittel-forschung 1997; 47: 734 - 745.

Aird WC. Spatial and temporal dynamics of the endothelium. J Thromb Haemost 2005; 3:13921406.

Amador-Licona N, Guizar-Mendoza J, Vargas E, Sanchez-Camargo G \& Zamora-Mata L. The short-term effect of a switch from glibenclamide to metformin on blood pressure and microalbuminuria in patients with type 2 diabetes mellitus. Arch Med Res 2000; 31:571-575.

Ametov AS, Demidova TIu, Kosykh SA.. [NO synthesis in the vascular endothelium of patients with type II diabetes]. Klin Med (Mosk)2005; 83(8):62-8

Ansell BJ, Watson KE, Weiss RE, et al. hsCRP and HDL Effects of Statins Trial (CHEST): rapid effect of statin therapy on C-reactive protein and high-density lipoprotein levels. A clinical investigation. Heart Dis 2003; 5:2-7.

Asagami T, Abbasi F, Stuelinger M, Lamendola C, McLaughlin T, Cooke JP, Reaven GM \& Tsao PS. Metformin treatment lowers asymmetric dimethylarginine concentrations in patients with type 2 diabetes. Metabolism 2002; 51:843-846. 
Avogaro A, Miola M, Favaro A, et al.. Gemfibrozil improves insulin sensitivity and flowmediated vasodilatation in type 2 diabetic patients. Eur J Clin Invest 2001; 31:603-9.

Balletshofer BM, Rittig K, Enderle MD, et al. Endothelial dysfunction is detectable in young normotensive first-degree relatives of subjects with type 2 diabetes in association with insulin resistance. Circulation 2000; 101:1780-4.

Bagi Z, Koller A, Kaley G.. Peroxisome proliferator-activated receptor activation increases NO bioavailability in coronary arterioles in type 2 diabetes by reducing oxidative stress. Am J Physiol Heart Circ Physiol 2004; 286:H742-8.

Beckman J A., A B. Goldfine, M B Gordon, L A. Garrett, J F. Keaney, Jr. and M A. Creager. Oral antioxidant therapy improves endothelial function in Type 1 but not Type 2 diabetes mellitus. Am J Physiol Heart Circ Physiol 2003; 285:2392-2398

Behrendt D, Ganz P. Endothelial function: from vascular biology to clinical applications. Am J Cardiol 2002; 90: 40L-48L.

Beisswenger PJ, Howell SK, Touchette AD, Lal S \& Szwergold BS. Metformin reduces systemic methylglyoxal levels in type 2 diabetes. Diabetes 1999; 48:198-202.

Bengel FM, Abletshauser C, Neverve J, et al. Effects of nateglinide on myocardial microvascular reactivity in Type 2 diabetes mellitus - a randomized study using positron emission tomography. Diabet Med 2005; 22:158-63.

Bhargava K, Hansa G, Bansal M, et al. Endothelium-dependent brachial artery flow mediated vasodilatation in patients with diabetes mellitus with and without coronary artery disease. J Assoc Physicians India 2003; 51:355-8.

Biegelsen ES, Loscalzo J. Endothelial function and atherosclerosis. Coron Artery Dis 1999; 10:241-56.

Bishop-Bailey D.. Peroxisome proliferator-activated receptors in the cardiovascular system. Br J Pharmacol 2000; 129:823-34.

Boden G, Shulman GIFree fatty acids in obesity and type 2 diabetes: defining their role in the development of insulin resistance and beta cell dysfunction. Eur J Clin Invest 2002; 32(Suppl 3):14-23.

Booth G, Stalker TJ, Lefer AM, et al. Mechanisms of amelioration of glucose-induced endothelial dysfunction following inhibition of protein kinase $\mathrm{C}$ in vivo. Diabetes 2002; 51:1556-64.

Bots M L A, W. Hoes, P J Koudstaal, A Hofman, D E Grobbee. Common Carotid IntimaMedia Thickness and Risk of Stroke and Myocardial Infarction.The Rotterdam Study. Circulation. 1997;96:1432-1437

Bremer Y, F Salloum, O Ockaili, E Chou, W Moskowitz, R Kukreja. Sildenafil citrate induces cardioprotective effects after ischemia/reperfusion injury in infant rabbits. Pediatr Res 2005; 57:22-28.

Burnier M: Angiotensin II type 1 receptor blockers. Circulation 2001; 103:904-912.

Busse R, Fleming I, Hecker M.. Signal transduction in endothelium dependent vasodilatation. Eur Heart J 1993; 14 (Suppl I):2-9.

Butler R, A D Morris, JJF. Belch, A Hill, A D Struthers. Allopurinol Normalizes Endothelial Dysfunction in Type 2 Diabetics With Mild Hypertension. Hypertension 2000; 35:746-751.

Caballero AE, Arora S, Saouaf R, et al. Microvascular and macrovascular reactivity is reduced in subjects at risk for type 2 diabetes. Diabetes 1999; 48:1856-62. 
Caballero AE, Saouaf R, Lim SC, et al.. The effects of troglitazone, an insulin-sensitizing agent, on the endothelial function in early and late type 2 diabetes: a placebocontrolled randomized clinical trial. Metabolism 2003; 52:173-80.

Calles-Escandon J, Ballor D, Harvey-Berino J, et al. Amelioration of the inhibition of fi brinolysis in elderly, obese subjects by moderate energy intake restriction. Am $J$ Clin Nutr 1996; 64:7-11.

Cardillo C, Campia U, Bryant MB, Panza JA. Increased activity of endogenous endothelin in patients with type II diabetes mellitus. Circulation 2002; 106:1783-1787.

Ceriello A, Cavarape a, Martinelli 1, DaRos R, Marra G, Quagliaro L, Piconi l, Assoli R, Motz $\mathrm{E}$ : The post-prandial state in type 2 diabets and endothelial dysfunction: effects of insulin aspart. Diabet Med 2004; 21:171-175.

Ceriello A: Impaired glucose tolerance and cardiovascular disease: the possible role of postprandial hyperglycemia. Am Heart J 2004; 14 803-807.

Ceriello A, Esposito K, Piconi L, Ihnat MA, Thorpe JE, Testa R, et al. Oscillating glucose is more deleterious to endothelial function and oxidative stress than mean glucose in normal and type 2 diabetic patients. Diabetes 2008; 57: 1349 - 1354.

Cerrato J, Hipoglucemia en la diabetes, fisiopatología, clínica y tratamiento. Medicine 2004; 17:1029-1033.

Chu NV, Kong AP, Kim DD, Armstrong D, Baxi S, Deutsch R, Caulfield M, Mudaliar SR, Reitz R, Henry RR \& Reaven PD. Differential effects of metformin and troglitazone on cardiovascular risk factors in patients with type 2 diabetes. Diabetes Care 2002; 25: 542-549.

Ciaraldi TP, Carter L, Seipke G, Mudaliar S, Henry RR. Effects of the long-acting insulin analog insulin glargine on cultured human skeletal muscle cells: comparisons to insulin and IGF-1. J Clin Endocrinol Metab 2001; 86:5838-5847.

Cleland SJ, Petrie JR, Small M, et al. Insulin action is associated with endothelial function in hypertension and type 2 diabetes. Hypertension 2000; 35 (1 Pt 2):507-11.

Cosentino F, Luscher TF. Endothelial dysfunction in diabetes mellitus. J Cardiovasc Pharmacol 1998; 32 (Suppl 3): S54-S61.

Cowan DB, Langille BL.. Cellular and molecular biology of vascular remodeling. Curr Opin Lipidol 1996; 7:94-100.

Creager MA, Luscher TF, Cosentino F, Beckman JA: Diabetes and vascular disease: pathophysiology, clinical consequences, and medical therapy: Part I. Circulation 2003; 108(12):1527-15323.

Cybulsky MI, Iiyama K, Li H, et al. A major role for VCAM-1, but not ICAM-1, in early atherosclerosis. J. Clin. Invest 2001; 107:1255-1262.

Dahlof B, Devereux RB, Kjeldsen SE, et al. Cardiovascular morbidity and mortality in the Losartan Intervention For Endpoint reduction in hypertension study (LIFE): a randomised trial against atenolol. Lancet 2002; 359:995-1003.

Dandona P, Aljada A.. Endothelial dysfunction in patients with type 2 diabetes and the effects of thiazolidinedione antidiabetic agents. J Diabetes Complications 2004; 18:91102.

De Jager J, Kooy A, Lehert P, Bets D, Wulffele MG, Teerlink T, Scheffer PG, Schalkwijk CG, Donker AJ \& Stehouwer CD. Effects of short-term treatment with metformin on markers of endothelial function and inflammatory activity in type 2 diabetes mellitus: a randomized, placebo-controlled trial. J Int Med 2005; 257: 100-109. 
De Luis DA, N Fernández, R. Aller. Homocisteína metabolismo y determinantes higiénico dietéticos. Endocrinol Nutr 2004; 51:458-463.

De Meyer GR, Herman AG. Vascular endothelial dysfunction. Prog Cardiovasc Dis 1997; 39:325-42.

Delles C, Jacobi J, Schlaich MP, John S, Schmieder RE: Assessment of endothelial function of the renal vasculature in human subjects. Am J Hypertens 2002; 15:3-9.

Dimmeler S, Haendeler J, Zeiher AM: Regulation of endothelial cell apoptosis in atherothrombosis. Current Opinion in Lipidology 2002; 13(5):531-536.

Dimmeler S, Zeiher AM: Vascular repair by circulating endothelial progenitor cells: the missing link in atherosclerosis?. Journal of Molecular Medicine 2004; 82(10):671-677

Duka I, Shenouda S, Johns $C$, et al. Role of the $\mathrm{B}(2)$ receptor of bradykinin in insulin sensitivity. Hypertension 2001; 38:1355-60.

Economides PA, L Khaodhiar, A Caselli, et al. The Effect of Vitamin E on Endothelial Function of Micro- and Macrocirculation and Left Ventricular Function in Type 1 and Type 2 Diabetic Patients. Diabetes 2005; 54:204-211.

Endemann DH, Schiffrin EL. Endothelial dysfunction. J Am Soc Nephrol 2004; 15: 1983- 1992.

Farhangkhoee H, Khan ZA, Kaur H, et al. Vascular endothelial dysfunction in diabetic cardiomyopathy: Pathogenesis and potential treatment targets. Pharmacol Ther 2006; 111:384-99.

Festa A, R D’Agostino, G Howard, L Mykkanen. Inflammation and microalbuminuria in nondiabetic and type 2 diabetic subjects: the insulin resistance atherosclerosis study. Kidney Int 2000; 58:1703-1710.

Forst T, Lubben G, Hohberg C, et al.. Infl uence of glucose control and improvement of insulin resistance on microvascular blood flow and endothelial function in patients with diabetes mellitus type 2 . Microcirculation 2005; 12:543-50.

Forstermann U, Munzel T. Endothelial nitric oxide synthase in vascular disease: from marvel to menace. Circulation 2006; 113:1708-1714.

Freed MI, Ratner R, Marcovina SM, et al. Effects of rosiglitazone alone and in combination with atorvastatin on the metabolic abnormalities in type 2 diabetes mellitus. Am J Cardiol 2002; 90:947-52.

Furchgott RF, Zawadzki JV. The obligatory role of endothelial cells in the relaxation of arterial smooth muscle by acetylcholine. Nature 1980; 288: 373-376.

Galie` N, HA Ghofrani, A Torbicki, RJ Barst, LJ Rubin. Sildenafil use in pulmonary arterial hypertension (SUPER) study group. N Engl J Med 2005; 353:2148-2157.

Galiè N, Ghofrani HA, Torbicki A, Barst RJ, Rubin LJ, Badesch D et al. Sildenafil citrate therapy for pulmonary arterial hypertension. N Engl J Med 2005; 353: 2148-2157.

Galle J, T Quaschning, S. Seibold, C. Wanner, Endothelial dysfunction and inflammation: what is the link? Kidney Int 2003; 84:545-549.

Gazis A, White DJ, Page SR, et al. Effect of oral vitamin E (a-tocopherol) supplementation on vascular endothelial function in type 2 diabetes mellitus. Diabet Med 1999; 16:30411.

Georgescu A, Popov D, Simionescu M. Mechanisms of decreased bradykinin-induced vasodilatation in experimental hyperlipemia-hyperglycemia: contribution of nitric oxide and Ca 2-actived Kchannel. Fundam Clin Pharmacol 2001; 15:335-342.

Giordano D, De Stefano ME, Citro G, Modica A, Giorgi M Expression of cGMP-binding cGMP-specific phosphodiesterase (PDE5) in mouse tissues and cell lines using an 
antibody against the enzyme amino-terminal domain. Biochim Biophys Acta 2001; 1539: 16-27.

Gomes MB, Affonso FS, Cailleaux S, Almeida AL, Pinto LF, Tibirica E: Glucose levels observed in daily clinical practice induce endothelial dysfunction in the rabbit macro- and microcirculation. Fundam Clin Pharmacol 2004; 18:339 -346.

Gori T, Sicuro S, Dragoni S, Donati G, Forconi S, Parker JD. Sildenafil prevents endothelial dysfunction induced by ischemia and reperfusion via opening of adenosine triphosphate-sensitive potassium channels: a human in vivo study. Circulation 2005; 111: 742-746.

Grover-Páez F, G Villegas-Rivera, R Guillén-Ortíz. Sildenafil citrate diminishes microalbuminuria and the percentage of A1c in male patients with type 2 diabetes. Diab Res Clinl Prac 2007; 78:136-140

Gross ER, LaDisa JF, Weihrauch D, Olson LE, Kress TT, Hettrick DA, Pagel PS, Warltier DC, Kersten1 JR: Reactive oxygen species modulate coronary wall shear stress and endothelial function during hyperglycemia. Am J Physiol Heart Circ Physiol 2003; 284:H1552-H1559.

Haefliger IO, Flammer J, Luscher TF. Nitric oxide and endothelin-1are important regulators of human ophthalmic artery. Invest Ophthalmol Vis Sci. 1992; 33:2340-3.

Halcox JP, Nour KR, Zalos G, Mincemoyer RA,Waclawiw M, Rivera CE et al. The effect of sildenafil on human vascular function, platelet activation, and myocardial ischemia. J Am Coll Cardiol 2002; 40: 1232-1240.

Hamilton SJ, GT Chew, GF Watts. Coenzyme Q10 Improves Endothelial Dysfunction in Statin-Treated Type 2 Diabetic Patients. Diabetes Care 2009; 32:810-812.

Heitzer T, Schlinzig T, Krohn K, Meinertz T, Munzel T. Endothelial dysfunction, oxidative stress, and risk of cardiovascular events in patients with coronary artery disease. Circulation 2001; 104:2673-2678

Hattori Y, Suzuki K, Hattori S \& Kasai K. Metformin inhibits cytokine-induced nuclear factor kappaB activation via AMP activated protein kinase activation in vascular endothelial cells. Hypertension 2006; 47: 1183-1188.

Hauner H.. The mode of action of thiazolidinediones. Diabetes Metab Res Rev 2002; 18(Suppl 2):S10-15.

Honisett SY, Stojanovska L, Sudhir K, et al.. Hormone therapy impairs endothelial function in postmenopausal women with type 2 diabetes mellitus treated with rosiglitazone. J Clin Endocrinol Metab 2004; 89:4615-9.

Hubacek J, Verma S, Shewchuk L, et al.. Rationale and design of the Glitazones and the Endothelium (GATE) study: evaluation of rosiglitazone on endothelial function in patients with diabetes. Can J Cardiol 2004; 20:1449-53.

Hundal RS \& Inzucchi SE. Metformin: new understandings, new uses. Drugs 2003; 63:18791894.

Huvers FC, De Leeuw PW, Houben AJ, et al. Endothelium-dependent vasodilatation, plasma markers of endothelial function, and adrenergic vasoconstrictor responses in type 1 diabetes under near-normoglycemic conditions. Diabetes 1999; 48:13001307.

Huszka M, Kaplar M, Rejto L, et al. The association of reduced endothelium derived relaxing factor-NO production with endothelial damage and increased in vivo platelet activation in patients with diabetes mellitus. Thromb Res 1997; 86: 173-180. 
Inokuchi K, Hirooka Y, Shimokawa H, Sakay K, Kishi T, Ito K, Kimura Y, Tekeshita A: Role of endothelium-derived hyperpolarizing factor in human forearm circulation. Hypertension 2003; 42:919 -924.

Inoue I, Itoh F, Aoyagi S, Tazawa S, Kusama H, Akahane M, Mastunaga T, Hayashi K, et al. Fibrate and statin synergistically increase the transcriptional activities of PPARalpha/RXRalpha and decrease the transactivation of NFkappaB. Biochem Biophys Res Commun 2002; 290:131-139

Inzucchi SE. Oral antihyperglycemic therapy for type 2 diabetes -scientific review. J Am Med Assoc 2002; 287:360-372.

Ishizuka T, Takamizawa-Matsumoto M, Suzuki K, et al. Endothelin-1 enhances vascular cell adhesion molecule-1 expression in tumor necrosis factor alpha-stimulated vascular endothelial cells. Eur J Pharmacol 1999; 369:237-245

Isoda K, Young JL, Zirlik A, MacFarlane LA, Tsuboi N, Gerdes N,Schönbeck U \& Libby P. Metformin inhibits proinflammatory responses and nuclear factor-kB in human vascular wall cells. Arteriosclerosis, Thrombosis, and Vascular Biology 2006; 26: 611-617.

Johnstone MT, Creager SJ, Scales KM, Cusco JA, Lee BK, Creager MA: Impaired endothelium-dependent vasodilation in patients with insulin-dependent diabetes mellitus. Circulation 1993; 88(6):2510-2516.

Kannel WB, McGee DL: Diabetes and cardiovascular disease. The Framingham study. JAMA 1979; 241(19):2035-2038.

Kim Y-B, Ciaraldi TP, Kong A, et al.. Troglitazone but not metformin restores insulinstimulated phosphoinositide 3-kinase activity and increases p110_ protein levels in skeletal muscle of type 2 diabetic subjects. Diabetes 2002; 51:443-8.

Komers R, Komersova K, Kazdova L, Ruzickova J, Pelikanova T: Effect of ACE inhibition and angiotensin AT1 receptor blockade on renal and blood pressure response to Larginine in humans. J Hypertens 2000; 18:51-5984.

Konukoglu D, Dogan E, Turhan MS, et al. Impaired glucose tolerance: its relevance to early endothelial dysfunction. Horm Metab Res 2003; 35:607-10.

Kuboki K, Jiang ZY, Takahara N, et al.. Regulation of endothelial constitutive nitric oxide synthase gene expression in endothelial cells and in vivo: a specifi c vascular action of insulin. Circulation 2000; 101:676-81.

Kukreja RC, Ockaili R, Salloum F, Yin C, Hawkins J, Das A et al. Cardioprotection with phosphodiesterase-5 inhibition-a novel preconditioning strategy. J Mol Cell Cardiol 2004; 36: 165-173.

Kurtzhals P, Schaffer L, Sorensen A, Kristensen C, Jonassen I, Schmid C, Trub T. Correlations of receptor binding and metabolic and mitogenic potencies of insulin analogs designed for clinical use. Diabetes 2000; 49:999-1005.

Lambert J, Aarsen M, Donker AJ, Stehouwer CD. Endothelium-dependent and independent vasodilation of large arteries in normoalbuminuric insulin-dependent diabetes mellitus. Arterioscler Thromb Vasc Biol 1996; 16:705-711.

Lee RT, Yamamoto C, Feng Y, et al. Mechanical strain induces specific changes in the synthesis and organization of proteoglycans by vascular smooth muscle cells. J. Biol. Chem 2001; 276:13847- 13851. 
Leinonen E, Hurt-Camejo E, Wiklund O, et al. Insulin resistance and adiposity correlate with acute-phase reaction and soluble cell adhesion molecules in type 2 diabetes. Atherosclerosis 2003; 166:387-94.

Leurs PB, Stolk RP, Hamulyak K, et al.. Tissue factor pathway inhibitor and other endothelium-dependent hemostatic factors in elderly individuals with normal or impaired glucose tolerance and type 2 diabetes. Diabetes Care 2002; 25:1340-5.

Li H, Cybulsky MI, Gimbrone MA Jr, et al. An atherogenic diet rapidly induces VCAM-1, a cytokine regulatable mononuclear leukocyte adhesion molecule, in rabbit endothelium. Arterioscler Thromb 1993; 13:197-204.

Libby P, Ridker PM, Maseri A. Inflammation in atherosclerosis. Circulation 2002; 105: 11351143.

Libby P. Inflammation in atherosclerosis. Nature 2002; 420:868-74.

Loomans CJ, De Koning EJ, Staal FJ, Rabelink TJ, Zonneveld AJ: Endothelial progenitor cell dysfunction in type 1 diabetes: another consequence of oxidative stress? Antioxidants \& redox signaling 2005; 7(11-12):1468-1475.

Lund S S., L Tarnow, C D. Stehouwer, C G. Schalkwijk, T Teerlink, J Gram. Impact of metformin versus repaglinide on non-glycaemic cardiovascular risk markers related to inflammation and endothelial dysfunction in non-obese patients with type 2 diabetes. Eur J Endo 2008; 158:631-641

Luscher TF, Tanner FC, Tschudi MR, et al. Endothelial dysfunction in coronary artery disease. Annu Rev Med 1993; 44:395-418.

Lyon CJ, Law RE, Hsueh WA. Mini review: adiposity, inflammation, and atherogenesis. Endocrinology 2003; 144:2195-200.

Mancini GB, Henry GC, Macaya C, et al. Angiotensin-converting enzyme inhibition with quinapril improves endothelial vasomotor dysfunction in patients with coronary artery disease. The TREND (Trial on Reversing ENdothelial Dysfunction) Study. Circulation 1996; 94:258-65.

Makino N, Maeda T, Sugano M, et al. High serum TNF-alpha level in Type 2 diabetic patients with microangiopathy is associated with eNOS down-regulation and apoptosis in endothelial cells. J Diabetes Complications 2005; 19:347-55.

Makoto Hiki, Kazunori Shimada, Takashi Kiyanagi, Kosuke Fukao, Kuniaki Hirose, Hiromichi Ohsaka. Single Administration of a-Glucosidase Inhibitors on Endothelial Function and Incretin Secretion in Diabetic Patients With Coronary Artery Disease. Circ J 2010; 74: 1471 - 1478.

Manson JE, Colditz GA, Stampfer MJ, Willett WC, Krolewski A, Rosner B, Arky RA, Speizer FE \& Hennekens $\mathrm{CH}$. A prospective study of maturity-onset diabetes mellitus and risk of coronary heart disease and stroke in women. Arch Int Med 1991; 151: 11411148.

Manzella D, Ragno E, Abbatecola AM, et al.. Residual C-peptide secretion and endothelial function in patients with Type II diabetes. Clin Sci 2003; 105:113-18.

Manzella D, Grella R, Abbatecola AM, et al. Repaglinide administration improves brachial reactivity in type 2 diabetic patients. Diabetes Care 2005; 28:366-71.

Mátthael,S M Stumvall, Pathophysiology and pharmacological treatment of insulin resistance. Endocr Rev 2001; 6: 585-618.4. 
McFarlane SI, Kumar A, Sowers JR.. Mechanisms by which angiotensin-converting enzyme inhibitors prevent diabetes and cardiovasculardisease. Am J Cardiol 2003; 91:30H$37 \mathrm{H}$

Meigs JB, Hu FB, Rifai N, et al. Biomarkers of endothelial dysfunction and risk of type 2 diabetes mellitus. JAMA 2004; 291:1978-86.

Milani E, Nikfar S, Khorasani R, Zamani MJ, Abdollahi M. Reduction of diabetes-induced oxidative stress by phosphodiesterase inhibitors in rats. Comp Biochem Physiol C Toxicol Pharmacol 2005; 140: 251-255.

Mita T, Otsuka A, Azuma K, Uchida T, Ogihara T, Fujitani Y, et al. Swings in blood glucose levels accelerate atherogenesis in apolipoprotein E-deficient mice. Biochem Biophys Res Commun 2007; 358:679 - 685.

Mombouli JV.. ACE inhibition, endothelial function and coronary artery lesions. Role of kinins and nitric oxide. Drugs 1997; 54 (Suppl 5):12-22.

Mudaliar S, Henry RR. New oral therapies for type 2 diabetesmellitus: the glitazones or insulin sensitizers. Annu Rev Med 2001; 52:239-57.

Nagi DK \& Yudkin JS. Effects of metformin on insulin resistance, risk factors for cardiovascular disease, and plasminogen activator inhibitor in NIDDM subjects. A study of two ethnic groups. Diabetes Care 1993; 16:621-629.

Natali A, Baldeweg S, Toschi E, Capaldo B, Barbaro D, Gastaldelli A, Yudkin JS \& Ferrannini E. Vascular effects ofimproving metabolic control with metformin or rosiglitazone in type 2 diabetes. Diabetes Care 2004; 27: 1349-1357.

Nathan DM, Lachin J, Cleary P, Orchard T, Brillon DJ, Backlund JY, O'Leary DH, Genuth S: Intensive diabetes therapy and carotid intima-media thickness in type 1 diabetes mellitus. N Engl J Med 2003; 348(23):2294-2303.

Nicholls SJ, E Murat, I Sipahi, et al. Effects of Obesity on Lipid-Lowering, AntiInflammatory, and Antiatherosclerotic Benefits of Atorvastatin or Pravastatin in Patients With Coronary Artery Disease (from the REVERSAL Study). Am J Cardiol 2006; 97:1553-1557.

O'Brien SF, Watts GF, Playaford DA, et al. Low-density lipoprotein size, high-density lipoprotein concentration, and endotelial dysfunction in non-insulin-dependent diabetes. Diab Med 1997; 14:974-978.

Oostrom O van, D PV de Kleijn, J O Fledderus, M Pescatori, A Stubbs, A Tuinenburg, et al. Folic acid supplementation normalizes the endothelial progenitor cell transcriptome of patients with type 1 diabetes: a case-control pilot study. Cardiovascular Diabetology 2009; 47: 1-11.

Ouvina SM, La Greca RD, Zanaro NL, et al.. Endothelial dysfunction, nitric oxide and platelet activation in hypertensive and diabetic type II patients. Thromb Res 2001; 102:107-14.

Paolisso G, MR Tagliamonte, M Barbieri, et al. Chronic Vitamin E Administration Improves Brachial Reactivity and Increases Intracellular Magnesium Concentration in Type II Diabetic Patients. J Clin Endocrinol Metab 2000; 85: 109-115.

Pendergrass M, Fazioni E, Collins D, Defronzo RA. IGF-I increases forearm blood flow without increasing forearm glucose uptake. Am J Physiol 1998; 275:E345-E350.

Perticone F, Ceravolo R, Candigliota M, et al. Obesity and body fat distribution induce endothelial dysfunction by oxidative stress: protective effect of vitamin C. Diabetes 2001; 50:159-65. 
Perticone F, Ceravolo R, Pujia A, Ventura G, Iacopino S, Scozzafava A, Ferraro A, Chello M, Mastroroberto P, Verdecchia P, Schillaci G. Prognostic significance of endothelial dysfunction in hypertensive patients. Circulation 2001; 104:191-196.

Piatti P, Fragasso G, Monti LD, Setola E, Lucotti P, Fermo I. Acute intravenous 1-arginine infusion decreases endothelin-1 levels and improves endothelial function in patients with angina pectoris and normal coronary arteriograms: correlation with asymmetric dimethylarginine levels. Circulation 2003; 107:429-436.

Pfutzner A, Marx N, Lubben G, Langenfeld M, Walcher D, Konrad T, Forst T: Improvement of cardiovascular risk markers by pioglitazone is independent from glycemic control: results from the Pioneer Study. J AmColl Cardiol 2005; 45:1925-1931.

Pistrosch F, Passauer J, Fischer S, et al. In type 2 diabetes, Rosiglitazone therapy for insulin resistance ameliorates endothelial dysfunction independent of glucose control. Diabetes Care 2004; 27:484-90.

Pistrosch F, Herbrig K, Kindel B, et al.. Rosiglitazone improves glomerular hyperfiltration, renal endothelial dysfunction, and microalbuminuria of incipient diabetic nephropathy in patients. Diabetes 2005; 54:2206-11.

Quehenberger P, Bierhaus A, Fasching P, et al. Endothelin 1 transcription is controlled by nuclear factor-kappaB in AGE-stimulated cultured endothelial cells. Diabetes 2000; 49: 1561-1570.

Quiñones MJ, Hernandez-Pampaloni M, Chon Y, et al.. Improvement of coronary artery endothelial dysfunction in insulin resistant patients after treatment with insulinsensitizing thiazolidinediones. Diabetes 2002; 51:A172.

Rask-Madsen C, Ihlemann N, Krarup T, Christiansen E, Kober L, Nervil KC, Torp-Pedersen C. Insulin therapy improves insulin-stimulated endothelial function in patients with type 2 diabetes and ischemic heart disease. Diabetes 2001; 50:2611-2618.

Reinhart K, O Baker, F Brunkhorst, Markers of endothelial damage in organ dysfunction and sepsis, Crit Care Med 2002; 30:5302-5312.

Retterstol L, B Paus, A Bakken. Plasma total homocysteine levels and prognosis in patients with previous premature myocardial infarction: a 10-year follow-up study. J Int Med 2003; 253:284-292.

Ridker PM, E Danielson, FAH Fonseca, et al. Rosuvastatin to Prevent Vascular Events in Men and Women with Elevated C-Reactive Protein. N Engl J Med 2008; 359:2195207151.

Ross R. The pathogenesis of atherosclerosis: a perspective for the 1990s. Nature 1993; 362: 801-809.

Salloum FN, Ockaili RA, Wittkamp M, Marwaha VR, Kukreja RC. Vardenafil: a novel type 5 phosphodiesterase inhibitor reduces myocardial infarct size following ischemia/reperfusion injury via opening of mitochondrial K(ATP) channels in rabbits. J Mol Cell Cardiol 2006; 40: 405-411

Satu Vehkavaara, Sari Ma“kimattila, Anna Schlenzka, Juha Vakkilainen, Jukka Westerbacka, Hannele Yki-Ja“rvinen. Insulin Therapy Improves Endothelial Function in Type 2 Diabetes. Arterioscler Thromb Vasc Biol 2000; 20:545-550

Satu Vehkavaara, Hannele Yki-Järvinen. 3.5 Years of Insulin Therapy With Insulin Glargine Improves In Vivo Endothelial Function in Type 2 Diabetes. Arterioscler Thromb Vasc Biol 2004; 24:325-330. 
Senzaki H, Smith CJ, Juang GJ, Isoda T, Mayer SP, Ohler A et al. Cardiac phosphodiesterase 5 (cGMP-specific) modulates beta adrenergic signaling in vivo and is downregulated in heart failure. FASEB J 2001; 15: 1718-1726.

Schachinger V, Britten MB, Zeiher AM. Prognostic impact of coronary vasodilator dysfunction on adverse long-term outcome of coronary heart disease. Circulation 2000; 101:1899-1906.

Schäfer A, Fraccarollo D, Pförtsch S, Flierl U, Vogt C, Pfrang J et al. Improvement of vascular function by acute and chronic treatment with the PDE-5 inhibitor sildenafil in experimental diabetes mellitus. Br J Pharmacol 2008; 153: 886-893.

Shabsigh R. Therapy of ED: PDE-5 Inhibitors. Endocrine 2004; 23: 135-141.

Schachinger V, Britten MB, Zeiher AM. Prognostic impact of coronary vasodilator dysfunction on adverse long-term outcome of coronary heart disease. Circulation 2000; 101: 1899-1906

Shepherd J, Cobbe SM, Ford I, et al. Prevention of coronary heart disease with pravastatin in men with hypercholesterolemia. West of Scotland Coronary Prevention Study Group. N Engl J Med 1995; 333:1301-7.

Schectman G, Hiatt J. Dose-response characteristics of cholesterol lowering drug therapies: implications for treatment. Ann Intern Med 1996; 125:990 -1000.

Sheetz MJ, King GL. Molecular understanding of hyperglycemia's adverse effects for diabetic complications. JAMA 2002; 288:2579-2588.

Shimabukuro M, Higa N, Takasu N, Tagawa T, Ueda S. A single dose of nateglinide improves postprandial endothelial dysfunction in type 2 diabetic patients. Diabet Med 2004; 21:983-986.

Shimabukuro Michio, Namio Higa, Ichiro Chinen, Ken Yamakawa, and Nobuyuki Takasu. Effects of a Single Administration of Acarbose on Postprandial Glucose Excursion and Endothelial Dysfunction in Type 2 Diabetic Patients: A Randomized Crossover Study. (J Clin Endocrinol Metab 2006; 91: 837-842.

Schmieder RE: Optimizing therapeutic strategies to achieve renal and cardiovascular risk reduction in diabetic patients with angiotensin receptor blockers. J Hypertens 2005; 23:905-911,

Schmieder RE. Impact of Telmisartan Versus Ramipril on Renal Endothelial Function in Patients With Hypertension and Type 2 Diabetes. Diabetes Care 2007; 30:1351-1356.

Schneider JG, Tilly N, Hierl T, et al. Elevated plasma endothelin-1 levels in diabetes mellitus. Am J Hypertens 2002; 15:967-972.

Shishehbor MH, Brennan ML, Aviles RJ, Fu X, Penn MS, Sprecher DL, Hazen SL. Statins promote potent systemic antioxidant effects through specific inflammatory pathways. Circulation 2003; 108:426-431.

Shishehbor MH, Aviles RJ, Brennan ML, Fu X, Goormastic M, Pearce GL, Gokce N, Keaney JF Jr, Penn MS, Sprecher DL, et al. Association of nitrotyrosine levels with cardiovascular disease and modulation by statin therapy. JAMA 2003; 289:16751680 .

Stalker TJ, Skvarka CB, Scalia R. A novel role for calpains in the endothelial dysfunction of hyperglycemia. FASEB J 2003; 17:1511-13.

Stoll LL, McCormick ML, Denning GM, Weintraub NL. Antioxidant effects of statins. Drugs Today (Barc) 2004; 40:975-990. 
Suwaidi JA, Hamasaki S, Higano ST, Nishimura RA, Holmes DRJ, Lerman A. Long-term follow-up of patients with mild coronary artery disease and endothelial dysfunction. Circulation. 2000; 101:948-954.

Svolis KA, Lemboussi DSP, Svolis AA, Stellas L, Bakopoulos C, Patronis A, Giannoulaki E: Telmisartan, an angiotensin II type 1 receptor blocker, improves endothelial function in patients with chronic heart failure (Abstract). J Am Coll Cardiol 2002; 39 (Suppl. B):266B.

Taddei S, Virdis A, Mattei P, Natali A, Ferrannini E, Salvetti A. Effect of insulin on acetylcholine-induced vasodilatation in normotensive subjects and patients with essential hypertension. Circulation 1995; 92:2911-2918.

Sheetz MJ, King GL: Molecular understanding of hyperglycemia's adverse effects for diabetic complications. JAMA 2002; 288(20):2579-2588.

Steinberg HO, Brechtel G, Johnson A, et al. Insulin-mediated skeletal muscle vasodilation is nitric oxide dependent. A novel action of insulin to increase nitric oxide release. $J$ Clin Invest 1994; 94:1172-9.

Steinberg HO, Chaker H, Leaming R, et al. Obesity/insulin resistance is associated with endothelial dysfunction: implications for the syndrome of insulin resistance. J Clin Invest 1996; 97:2601-10.

Studdy PR, Lapworth R, Bird R. Angiotensin-converting enzyme and its clinical significance-a review. J Clin Pathol 1983; 36:938-47.

Stuhlinger MC, Abbasi F, Chu JW, et al.. Relationship between insulin resistance and an endogenous nitric oxide synthase inhibitor. JAMA 2002; 287:1420-6.

Tan KC, Chow WS, Ai VH, et al. Effects of angiotensin II receptor antagonist on endothelial vasomotor function and urinary albumin excretion in type 2 diabetic patients with microalbuminuria. Diabetes Metab Res Rev 2002; 18:71-6.

Testa R, Bonfigli AR, Piantanelli L, Manfrini S, Testa I \& Gregorio F. Relationship between plasminogen activator inhibitor type-1 plasma levels and the lipoprotein(a) concentrations in noninsulin-dependent diabetes mellitus. Diab Res Clin Prac 1996; 33: 111-118.

Thorand B, Baumert J, Chambless L, et al. MONICA/KORA Study Group. Elevated markers of endothelial dysfunction predict type 2 diabetes mellitus in middle-aged men and women from the general population. Arterioscler Thromb Vasc Bio 2006; 26:398-405.

Tornel,PL J Abellán, A Cano, P Martínez, La proteína C reactiva como marcador del riesgo cardiovascular, Hipertensión 2003; 20:74-81.

Takemoto M, Liao JK. Pleiotropic effects of 3-hydroxy-3-methylglutaryl coenzyme A reductase inhibitors. Arterioscler Thromb Vasc Biol 2001; 21:1712-1719.

Tamai O, Matsuoka H, Itabe $\mathrm{H}$, et al. Single LDL apheresis improves endotheliumdependent vasodilatation in hypercholesterolemic humans. Circulation 1997; 95:7682.

Teixeira CE, Priviero FB, Webb RC Differential effects of the phosphodiesterase type 5 inhibitors sildenafil, vardenafil, and tadalafil in rat aorta. J Pharmacol Exp Ther 2006; 316: 654-661.

UK Prospective Diabetes Study (UKPDS) Group. Effect of intensive blood-glucose control with metformin on complications in overweight patients with type 2 diabetes (UKPDS 34). Lancet 1998; 352:854-865. 
UK Prospective Diabetes Study Group. Intensive blood-glucose control with sulphonylureas or insulin compared with conventional treatment and risk of complications in patients with type 2 diabetes (UKPDS 33). Lancet 1998; 352:837-853.

Vehkavaara S, Si Ma“kimattila, A Schlenzka, Ja Vakkilainen, J Westerbacka, H Yki-Ja"rvinen. Insulin Therapy Improves Endothelial Function in Type 2 Diabetes. Arterioscler Thromb Vasc Biol 2000;20:545-550.

Viberti GC, Benigni A, Bognetti E, et al.. Glomerular hyperfiltration and urinary prostaglandins in type 1 diabetes mellitus. Diabet Med 1989; 6:219-23.

Vita JA, Keaney JF. Endothelial function: a barometer for cardiovascular risk? Circulation 2002; 106: 640-642.

Volpe Massimo, Castello Lorenzo, Cosentino Francesco. Effects of Olmesartan on Endothelial Function. High Blood Pressure Cardiov Prevention 2007; 14 (4): 221-227.

Vallejo S, Angulo J, Peiro C, Cercas E, Sanchez-Ferrer A, Nevado J. Treatment with acarbose may improve endothelial dysfunction in streptozotocin-induced diabetic rats. $J$ Cardiovasc Pharmacol 2000; 36:255-262.

Vlachopoulos C, Tsekoura D, Alexopoulos N, Panagiotakos D, Aznaouridis K, Stefanadis C). Type 5 phosphodiesterase inhibition by sildenafil abrogates acute smokinginduced endothelial dysfunction. Am J Hypertens 2004; 17: 1040-1044.

Vehkavaara S, Mäkimattila S, Schlenzka A, Vakkilainen J, Westerbacka J, Yki-Järvinen H. Insulin therapy improves endothelial function in type 2 diabetes. Arterioscler Thromb Vasc Biol 2000; 20:545-550.

Wautier JL, Zoukourian C, Chappey O, et al. Receptor mediated endothelial cell dysfunction in diabetic vasculopathy. Soluble receptor for advanced glycation end products blocks hyperpermeability in diabetic rats. J Clin Invest, 1996; 97:238-

Wakino S, Law RE, Hsueh WA.. Vascular protective effects by activation of nuclear receptor PPAR. J Diab Com 2002; 16:46-9.

Williams SB, Cusco JA, Roddy MA, Johnstone MT, Creager MA: Impaired nitric oxidemediated vasodilation in patients with non-insulin-dependent diabetes mellitus. Journal of the American College of Cardiology 1996; 27(3):567-574.

Wajcberg E, Sriwijilkamol A, Musi N, De-Fronzo R, Cersosimo E: Relationship Between vascular reactivity and lipids in Mexican American with T2DM treated with pioglitazone. J Clin Endocrinol Metab 2007; 92:1256-1262.

Wen Y, Skidmore JC, Porter-Turner MM, et al. Relationship of glycation, antioxidant status and oxidative stress to vascular endothelial damage in diabetes. Diabetes Obes Metab 2002; 4:305-8.

Williams B. A potential role for angiotensin II-induced vascular endothelial growth factor expression in the pathogenesis of diabetic nephropathy? Miner Electrolyte Metab 1998; 24:400-5.

Yano M, Hasegawa G, Ishii M, Yamasaki M, Fukui M, Nakamura N, Yoshikawa T. Shortterm exposure of high glucose concentration induces generation of reactive oxygen species in endothelial cells: implication for the oxidative stress associated with postprandial hyperglycemia. Redox Rep 2004: 9:111-116.

$\mathrm{Yu}$ Y, Suo L, Yu H, et al.. Insulin resistance and endothelial dysfunction in type 2 diabetes patients with or without microalbuminuria. Diabetes Res Clin Pract 2004; 65:95104. 
Yusuf S, Gerstein H, Hoogwerf B, et al.. Ramipril and the development of diabetes. JAMA 2001; 286:1882-5.

Zeng G, Nystrom FH, Ravichandran LV, et al.. Roles for insulin receptor, PI3-kinase, and Akt in insulin-signaling pathways related to production of nitric oxide in human vascular endothelial cells. Circulation 2000; 101:1539-45. 


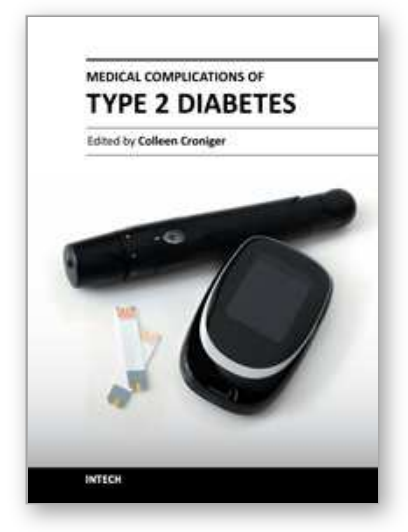

\author{
Medical Complications of Type 2 Diabetes \\ Edited by Dr. Colleen Croniger
}

ISBN 978-953-307-363-7

Hard cover, 412 pages

Publisher InTech

Published online 12, September, 2011

Published in print edition September, 2011

Obesity and type 2 diabetes are increasing worldwide problems. In this book we reviewed insulin secretion in both healthy individuals and in patients with type 2 diabetes. Because of the risk associated with progression from insulin resistance to diabetes and cardiovascular complications increases along a continuum, we included several chapters on the damage of endothelial cells in type 2 diabetes and genetic influences on endothelial cell dysfunction. Cardiovascular complications occur at a much lower glucose levels, thus a review on the oral glucose tolerance test compared to other methods was included. The medical conditions associated with type 2 diabetes such as pancreatic cancer, sarcopenia and sleep disordered breathing with diabetes were also discussed. The book concludes with several chapters on the treatments for this disease offering us hope in prevention and successful alleviation of the co-morbidities associated with obesity and type 2 diabetes.

\title{
How to reference
}

In order to correctly reference this scholarly work, feel free to copy and paste the following:

Fernando Grover Páez (2011). Endothelial Dysfunction and Therapeutic Intervention in Type 2 Diabetes, Medical Complications of Type 2 Diabetes, Dr. Colleen Croniger (Ed.), ISBN: 978-953-307-363-7, InTech, Available from: http://www.intechopen.com/books/medical-complications-of-type-2-diabetes/endothelialdysfunction-and-therapeutic-intervention-in-type-2-diabetes

\section{INTECH}

open science | open minds

\author{
InTech Europe \\ University Campus STeP Ri \\ Slavka Krautzeka 83/A \\ 51000 Rijeka, Croatia \\ Phone: +385 (51) 770447 \\ Fax: +385 (51) 686166 \\ www.intechopen.com
}

\author{
InTech China \\ Unit 405, Office Block, Hotel Equatorial Shanghai \\ No.65, Yan An Road (West), Shanghai, 200040, China \\ 中国上海市延安西路65号上海国际贵都大饭店办公楼405单元 \\ Phone: +86-21-62489820 \\ Fax: +86-21-62489821
}


(C) 2011 The Author(s). Licensee IntechOpen. This chapter is distributed under the terms of the Creative Commons Attribution-NonCommercialShareAlike-3.0 License, which permits use, distribution and reproduction for non-commercial purposes, provided the original is properly cited and derivative works building on this content are distributed under the same license. 